\title{
Workshop Report: Research Roadmap for Reducing the Fire Hazard of Materials in the Future
}

\author{
Rick Davis \\ Mauro Zammarano \\ Nathan Marsh \\ Fire Research Division \\ Engineering Laboratory \\ Paget Donnelly \\ Shawna McQueen \\ Anand Raghunathan \\ Energetics Incorporated
}

This publication is available free of charge from: https://doi.org/10.6028/NIST.SP.1220

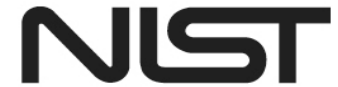

National Institute of Standards and Technology U.S. Department of Commerce 


\title{
Workshop Report: \\ Research Roadmap for Reducing \\ the Fire Hazard of Materials \\ in the Future
}

\author{
Rick Davis \\ Mauro Zammarano \\ Nathan Marsh \\ Fire Research Division \\ Engineering Laboratory \\ Paget Donnelly \\ Shawna McQueen \\ Anand Raghunathan \\ Energetics Incorporated
}

This publication is available free of charge from:

https://doi.org/10.6028/NIST.SP.1220

March 2018

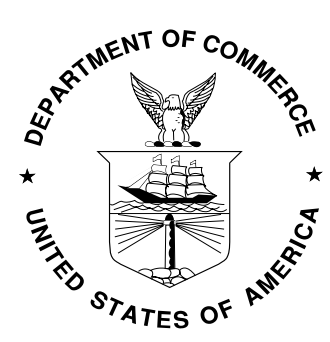

U.S. Department of Commerce Wilbur L. Ross, Jr., Secretary 


\section{DISCLAIMER}

This report was prepared as an account of work cosponsored by NIST. The views and opinions expressed herein do not necessarily state or reflect those of NIST. Certain commercial entities, equipment, or materials may be identified in this document in order to illustrate a point or concept. Such identification is not intended to imply recommendation or endorsement by NIST, nor is it intended to imply that the entities, materials, or equipment are necessarily the best available for the purpose.

National Institute of Standards and Technology Special Publication 1220

Natl. Inst. Stand. Technol. SP 1220, 54 pages (March 2018) 
This page is intentionally left blank. 


\section{ACKNOWLEDGEMENTS}

This report is based on the results of the Future Needs for Reducing the Fire Hazard of Materials Workshop held on August 18-19, 2016, in Gaithersburg, Maryland. The workshop was sponsored by the National Institute of Standards and Technology (NIST), an agency of the U.S. Department of Commerce. A sincere thank you is extended to NIST organizers. A special thank you to the speakers and panelists who provided their perspectives on future opportunities, needs, and challenges for fire-resistant materials. We also appreciate the contributions of all the workshop participants, listed in Appendix A; this report would not have been possible without their valuable knowledge and insight. Lastly, thank you is extended to the Energetics Incorporated team for facilitating the workshop and the first draft of this report.

\section{Plenary Speakers}

Howard Harary, Director, Engineering Laboratory, NIST

Rick Davis, Leader, Flammability Reduction Group, Engineering Laboratory, NIST

\section{Panel: Innovative Construction Materials}

\section{Speakers}

David Barber, Arup

Kuma Sumathipala, American Wood Council

Paul Shipp, U.S. Gypsum

\section{Additional Panelists}

Dan Cheney, Boise Cascade

Tyler Congleton, Boise Cascade

David Johnston, Vinyl Siding Institute

Panel: Advanced Polymers and Composites

Alex Morgan, Univ. of Dayton Research

Institute

Yu-Zhong Wang, Sichuan University
Yuan Hu, Univ. of Science \& Technology, China

David Schiraldi, Case Western University

Panel: Next Generation Fire Retardants

Douglas Fox, American University

Manfred Döring, Fraunhofer Institute
Charles Olsen, AB Specialty Silicones

Panel: Transportation and Infrastructure
Mark Gentile, U.S. Department of

Transportation

Brian Lattimer, Jensen Hughes
Baljinder Kandola, University of Bolton

Usman Sorathia, U.S. Navy

\section{NIST Organizers \\ Rick Davis \\ Nathan Marsh \\ Mauro Zammarano}




\section{CONTENTS}

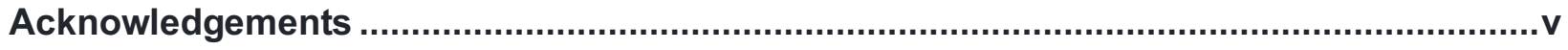

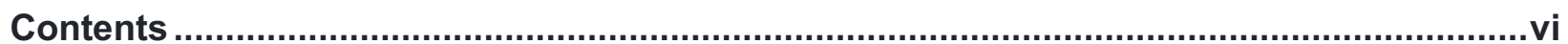

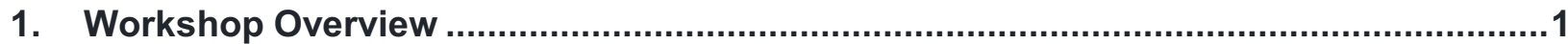

1.1. National Institute of Standards and Technology (NIST) …............................... 1

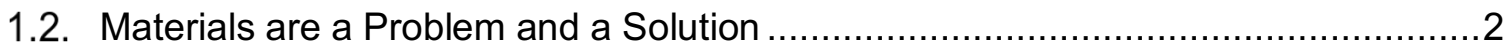

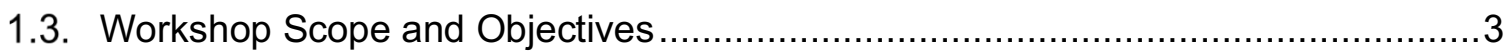

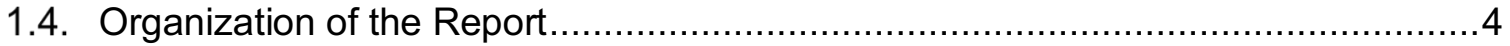

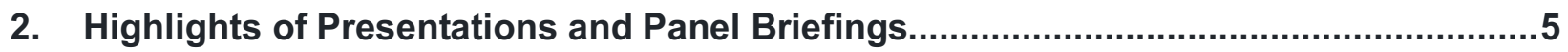

2.1. Innovative Construction Materials ..............................................................

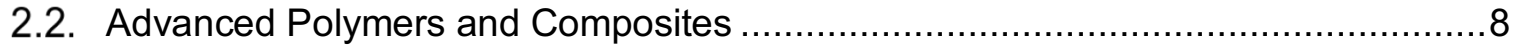

2.3. Next-Generation Fire Retardants ................................................................. 10

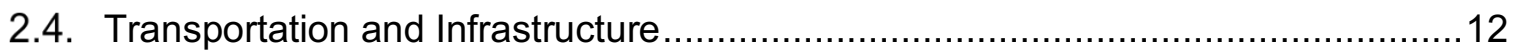

3. Fire Hazards - Applications and Challenges............................................................14

3.1. Applications Requiring Future Fire Reduction Efforts.....................................14

3.2. Research Needs and Implementation Plans for Priority Applications ...................20 3.2.1. Building Construction Applications ..........................................22

3.2.2. Building Interior Applications ..................................................28

3.2.3. Cross-Cutting Approaches ……………………………........ 32

4. Highest Priority Research and Recommendations ....................................................39

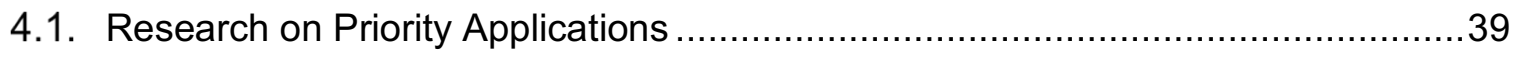

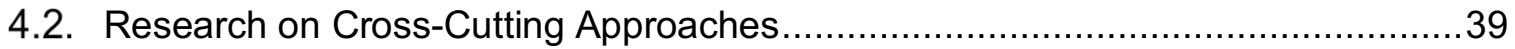

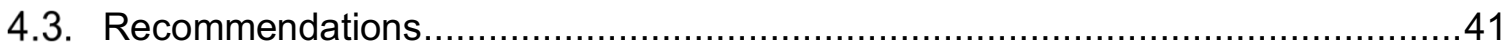

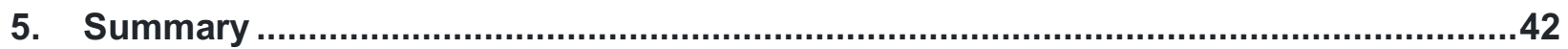

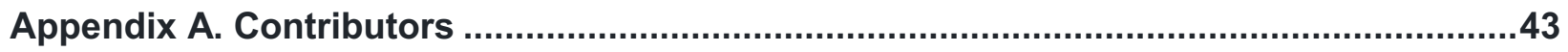

Appendix B. Acronyms/Abbreviations ..............................................................................

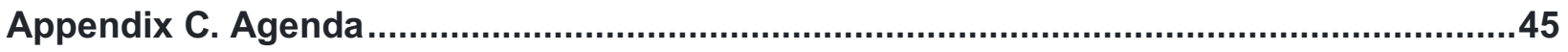


This page is intentionally left blank. 
금

$\stackrel{0}{<}$

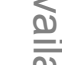

$\frac{\sigma}{D}$

$\overrightarrow{\mathbb{D}}$

윽

తి

(1)

욱

䒜

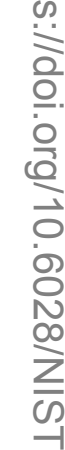

os

N

○ 


\section{WORKSHOP OVERVIEW}

\subsection{National Institute of Standards and Technology (NIST)}

The National Institute of Standards and Technology (NIST) is a Federal laboratory with a mission to enhance the nation's industrial competitiveness. NIST supports U.S. competitiveness in cybersecurity, disaster resilience, quantum science, and advanced manufacturing, materials and communications. In fulfilling this mission, NIST is improving the economy, security, and quality of life of the nation.

NIST meets its mission through a combination of intramural laboratory research and extramural collaborative programs aimed at removing barriers in measurement science, standards, and technology.

NIST is the only Federal organization in the U.S. that has the mission to deliver the measurement science necessary for U.S. competitiveness and security. Without well-understood, verified measurements, every step in the product development and commercialization cycle stalls - from invention to refinement, and manufacture to sales.

NIST develops and disseminates measurement standards and calibration services to help ensure that measurements made by precision instruments and sensors in every industry are reliable and can be trusted to advance research and commercialize high quality and safe products. In addition, NIST technical staff lends their unbiased expertise to private and international organizations that develop consensus standards about performance, compatibility, and safety of a product.

NIST's role in technologies focuses on the U.S. economy and the measurements needed for U.S. commercialization. There are many associated barriers and challenges in areas like interoperability, security, usability, performance, and resiliency. NIST enables the U.S. to overcome these challenges by engaging with government and industry stakeholders to develop the measurement science solutions and technologies, standards, prototypes, and guidelines essential for technology adoption and dissemination.

While NIST is eager to address every science and engineering challenge facing this nation, the reality is, some challenges are best left for others to address because, for example, NIST doesn't have the expertise or the resources, the area is outside the scope of NIST's mission, or the market will likely take care of itself. Knowing what challenges to address, how to address them, when to address them, and what solutions are best for the market requires extensive conversations between NIST researchers and the relevant external stakeholders. To gain understanding and stimulate collaboration within the market, a common approach at NIST is to conduct a workshop with subject matter experts and respected colleagues in the fields of science and engineering.

The Fire Research Division at NIST develops, verifies, and applies measurements and predictive methods to

Furniture Flammability Research NIST conducting research to predict the burning behavior of residential upholstered furniture (RUF) based on its construction, component material flammability, and thermo-physical properties. This capability could help furniture manufacturers design and deliver low-flammability RUF.

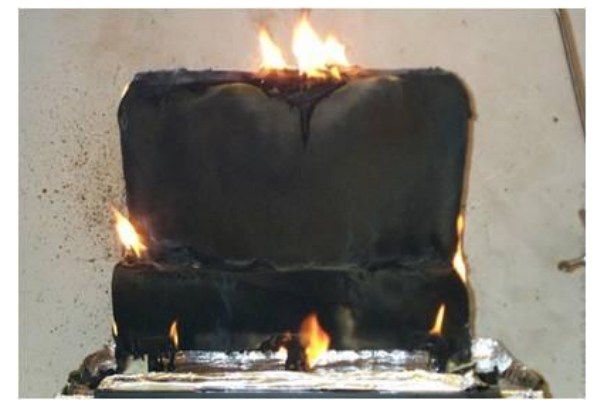

Barrier fabric test shows no flame penetration after six minutes. (Photo: NIST) aid in quantifying the behavior of fires and reduce their impact on people, property, and the environment. These activities integrate laboratory measurements, verified predictive methods, and large-scale fire experiments. The purpose of this workshop, Future Needs for Reducing the Fire Hazard of Materials, is 
to provide input to the Fire Division at NIST and relevant stakeholders to identify what are the applications, measurement science needs, and challenges related to reducing the fire hazards of existing and future materials and products that compose the built and manufactured environment.

\subsection{Materials are a Problem and a Solution}

More than million fires occur each year causing thousands of deaths and injuries and billions of dollars in property damage. According the National Fire Protection Association (NFPA), in 2016, 1.34 million fires occurred causing 3200 civilian deaths, 15000 civilian injuries, and $\$ 10$ billion in property damages. ${ }^{1}$ "Structures fires" account for only $35 \%$ (475 500) of the 1.34 million fires -1 fire every $60 \mathrm{~s}$. However, they are the most deadly and destructive, accounting for more civilian deaths (2 950), civilian injuries (12 775 ) and property damage ( $\$ 7.9$ billion) then all other fires combined. "Outside and other fires" occurred most frequently $(662500,49 \%)-1$ fire every $48 \mathrm{~s}$. These fires are responsible for the $2^{\text {nd }}$ highest losses of all fires with 85 civilian deaths, 650 civilian injuries, and $\$ 1.5$ billion in property damage. $\$ 911$ million in property damage occurred in a one major Wildland Urban Interface fire in Gatlinburg, Tennessee. Vehicle fires account for the remaining $16 \%$ of the fires. "Highway vehicle fires" $(173,000$, $13 \%$ ) account for 280 civilian deaths, 1075 civilian injuries and $\$ 0.93$ billion in property damage. "Other vehicle fires", such as planes, trains, and ships, (31 000, $2 \%$ ) account for 75 civilian deaths, 150 civilian injuries, and $\$ 0.42$ million in property damage.

The best approach to reduce a hazard is to eliminate the source or, if unable to eliminate entirely, replace the source with something less hazardous. For reducing fire hazards, this simply means eliminate the use of materials and products that burn - if it doesn't burn then there isn't a fire. Due to a number of factors (e.g.; product attributes desired by the customer and product manufacturability) it is likely a majority of the materials chosen will continue to pose an unacceptable fire hazard. When elimination isn't a solution, manufacturers have relied on reducing the fire hazard with the incorporation of chemical and physical fire retardant (FR) technologies. However, the FR options available to manufacturers are drastically dwindling due to health and safety concerns for most frequently used FRs; a trend that will likely continue in the future. , $^{2,4,5}$

Fire regulations define test methods and performance metrics that ensure products meet an acceptable fire risk when in their end-use applications (e.g.; construction and contents of commercial and residential buildings, and transportation vehicles). Test methods that utilize the real product under scenarios comparable to the end-use can be quite expensive, but they generally provide results more easily translated in real world performance. Small/bench scale tests are typically less expensive, quicker, safer, and require less material. However, translating these results to real world performance is exceptionally difficult for many reasons (e.g.; material interactions, geometry contributions, and flame behavior can change unpredictably with scale). In the future, due to the increased restriction on FRs, an emphasis to drive down costs, and to respond quickly to the ever-changing market, the fire community will rely more heavily on bench-scale methods for material and product development, and fire safety compliance testing.

\footnotetext{
${ }^{1}$ Hayned, H.; Fire Loss in the United States. National Fire Protection Association. September 2017. http://www.nfpa.org/Newsand-Research/Fire-statistics-and-reports/Fire-statistics/Fires-in-the-US/Overall-fire-problem/Fire-loss-in-the-United-States, last viewed November 28, 2017.

2 “Furniture Recycling's Catch-22: the Flame Retardant Industry's Toxic Legacy.” Jamie Rhodes, Program Director, Upstream, December 9, 2015. http://upstreampolicy.org/furniture-recyclings-catch-22-the-flame-retardant-industrys-toxic-legacy/, last viewed November 28, 2017

${ }^{3}$ https://www.lexology.com/library/detail.aspx?g=e41a8b83-8975-499f-8160-ab298a0e7e46, last viewed November 28, 2017.

${ }^{4}$ http://www.chicagotribune.com/news/watchdog/ct-cpsc-flame-retardants-ban-met-20170919-story.html, last viewed on November 28, 2017.

${ }^{5}$ Babrauskas, V.; Blum, A.; Daley, R.; Birnbaum, L.; Flame Retardants in Furniture Foam: Benefits and Risks,

Fire Safety Science - Proceedings of the $10^{\text {th }}$ International Symposium, 2011, 265-278, DOI: 10.3801/IAFSS.FSS.10-265.
} 
To accomplish this, more confidence in the test methods (existing or new) to accurately measure realworld fire performance is needed. Undesirable consequences have both significantly complicated new engineering for fire safety and opened new opportunities to "do the job better."

In the $21^{\text {st }}$ century, we can expect the built environment, consumer products, and modes of transportation to continue evolving and changing. With changes, we should expect new paradigms in fire safety. Innovations that improve the quality of life in some ways could create fire protection challenges that did not exist before. While research to reduce fire hazards is ongoing in many critical areas, there is a need to understand and anticipate the challenges to fire hazards that may arise as modernization continues. New technologies, materials, products, testing standards and regulations may help to reduce those fire hazards.

\subsection{Workshop Scope and Objectives}

NIST conducted a workshop on the Future Needs for Reducing the Fire Hazard of Materials on August 19-20, 2016, in Gaithersburg, Maryland. Key stakeholders from industry, academia, government, and public laboratories from the U.S and abroad participated. They contributed their expert views on future applications, needs, and challenges related to reducing the fire hazards of existing and future materials and products that compose the built and manufactured environment. The objective was to gather and distribute information that could enable the global fire community to develop a multi-year research and development $(\mathrm{R} \& \mathrm{D})$ plan to improve the fire resistance of products. The workshop attendees were asked to emphasize the development of new materials; technologies; reference materials; measurement and test methods; product flammability standards, and computational algorithms to reduce the fire hazard of building contents and construction materials. The participants were also asked to consider emerging technologies and practices, such as the increasing use of high energy density batteries, while not currently in widespread usage as of 2016, can be expected to be so in the future, and are becoming widespread as of the publishing of this report.

Based on preliminary brainstorming by NIST staff and external stakeholders the workshop focused on four areas in which fire hazards are a major concern:

- Innovative Construction Materials

- Advanced Polymers and Composites

- Next Generation Fire Retardants

- Transportation and Infrastructure

Please note that the ideas presented here and during the workshop reflect the views of the individuals at the workshop and not necessarily those of the entire fire safety communities. The views of these individuals are valuable because of their expertise, knowledge, and experience in reducing the fire hazards of materials. However, since fire material science is a global and multidisciplinary field the information within this report should be considered as a snapshot of important perspectives and there are likely other very important perspectives not captured here.

It is our hope that the information within this report will be used to guide the research in academia, and the public and private sector. The NIST Fire Research Division intends to consider the input from this workshop as the Fire Research Division updates its research roadmap for addressing the measurement science gaps that are preventing the nation from developing low fire hazard products now and in the future. 


\section{Workshop Process}

An overview of the facilitated process for the workshop is shown in Figure 1.1

The workshop opened with presentations and panel discussions by experts in each field (Innovative Construction Materials, Advanced Polymers and Composites, Next Generation Fire Retardants, and Transportation and Infrastructure). As a single group, participants took part in a series of brainstorming and discussion sessions to develop a list of potentially significant applications and approaches, focused on fire-resistant materials. Then, as individual experts, each suggested a few applications and approaches they believed to have the highest priority (most critical and urgent applications and approaches in terms of overall impact on the fire problem). The workshop organizers compiled the expert's responses into a prioritized list of applications and approaches. Three breakout groups were formed, and each assigned to a) complete a discussion and review of the top four applications/approaches, and b) identify additional applications and approaches from a reduced list of the remaining ones. The intent was for all three breakout groups to only review these top four applications/approaches. Since the groups went through the assignment at different rates, we ended up with more than four applications/approaches reviewed. However, since the groups independently selected these topics, not all the applications/approaches were reviewed by all three breakout groups.

\section{Figure 1.1. Workshop Process}

- Applications and Approaches: Questions were provided to the participants prior to the workshop, including:

- In the future (10 to 20 years) what applications would benefit from increasing fire safety at the material level?

- What are the challenges facing these applications?

- What are potential approaches for addressing these novel applications and challenges (materials, technology, test methods, etc.)?

- At the workshop, nine presentations were given to stimulate the thinking of the workshop participants

- A brainstorming session composed of all the participants generated a comprehensive list of applications and approaches, as well as the associated challenges and undesirable consequences

- Participants were asked to draw on their individual knowledge and experience to identify the most critical and urgent applications and approaches in terms of overall impacts on the fire problem.

- Interactive small group sessions produced action plans for the most important applications and approaches identified; these plans include:

- Research needed to move forward with approaches / solutions and fill gaps

- Potential undesirable consequences if the approaches are applied successfully

- Factors / metrics to guide research in these areas

- Performance targets, outcomes, milestones and timing

- Stakeholders who should be involved and their roles

\subsection{Organization of the Report}

The applications and challenges identified during the August 2016 workshop provide the foundation of this report. Sections addressing R\&D for important applications, as well as some of the cross-cutting $\mathrm{R} \& \mathrm{D}$ may be required to meet future challenges for fire protection.

Appendix A lists the workshop participants. Appendix B provides a list of the acronyms and abbreviations found throughout the report. 


\section{Highlights of Presentations and Panel BRIEFINGS}

A number of speakers and panelists provided expert insights on what the future holds for reducing the fire hazards in several applications. These projections and insights are summarized briefly below.

\section{Welcome and Workshop Introduction}

Welcome - Howard Harary, Director, NIST Engineering Laboratory, welcomed the Workshop participants to NIST and provided an overview of the laboratory and its efforts in fire research.

Workshop Purpose and Objectives - Rick Davis, NIST - Fire Research Division, outlined the scope of the Workshop and its objectives. Participants were asked to envision how the living environment (homes, transportation, businesses, and communications) is likely to change over the next two decades and identify the accompanying potential challenges for fire reduction.

\subsection{Innovative Construction Materials}

Tall Wood Buildings: Fire Safety Issues and Solutions: David Barber, Arup, addressed the growing popularity of tall wood buildings, especially those constructed with cross-laminated timber (CLT). CLT panels are a manufactured wood product made of dimensional lumber and adhesive and they are assembled at the manufacturing facility for use in load-bearing walls and other structural components. Driven by sustainability, aesthetics and affordability, newer wood building technologies have become relatively common in Europe and have been moving into Asia, Australia, Canada, and recently the United States. The tallest wood buildings today are planned for Austria (27 floors) and Sweden (32 floors). More modest high-rise wood structures are proposed for New York City (10 floors) and Portland, Oregon (12 floors).

There are concerns about the fire retardant properties of the newer

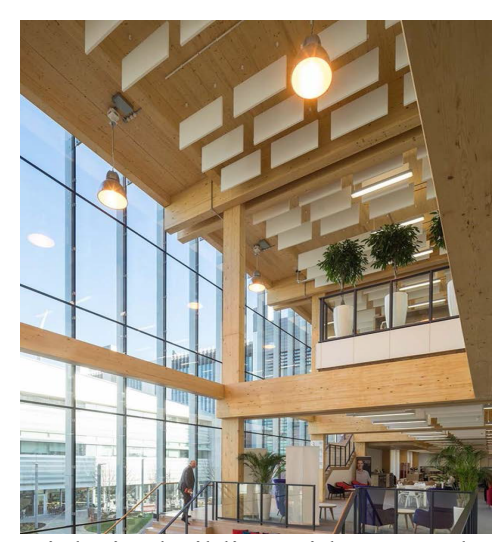

High rise building with exposed wood construction. (Source: Barber's presentation). products used in tall wood buildings. Mr. Barber pointed out that combustibility is just another engineering problem and all materials are vulnerable to fire. At least wood timbers possess some inherent resistance (based on mass and the insulating properties of the char layers that develop during fire exposure - assuming the use of a thermoset resin adhesive). However, timber alone has it limits, as does all materials, which diminishes the scope of how timber can be used (i.e., building height). A challenge is to find cost effective and environmentally friendly options that provide the aesthetics desired by the building/home owner and the structural and fire load requirements described in building codes.

In some cases, there are existing technologies, materials, and products being implemented in other countries that need to be tested or adapted to meet U.S. requirements. For example, does engineered wood product solutions that have achieved a 90 min burn time overseas meet the 120 min requirement for the U.S. market? If not, a challenge would be to develop affordable and easily adoptable solutions, which meet this more stringent criteria (e.g.; a material that drops into the existing manufacturing process or is a post-manufacturing treatment)?

In Europe, the building codes have been updated based on the CLT. What is missing in the U.S.? In the U.S., there is little research to fully understand the fire behavior of engineered wood, including interior 
material finishes, fire ratings for structural frames, fire dynamics (heat release rates and durations), connections, adhesives, encapsulation solutions, and fire-protective coatings. What we know about timber construction is based on light weight timber - used in homes - and limited research on heavy timbers - used for high-rise buildings. High-rise buildings require the use of heavy timber, which doesn't have the same fire performance as lightweight timber. Mr. Barber suggests research on full-scale fire experiments is needed to better understand vulnerabilities and behavior in real world. Also, research is needed to develop bench scale performance and computational tools aligned with the results from the fullscale experiments. The combination of data from the full-scale, bench-scale, and computational research will provide the basis for performance testing standards, regulations and codes, and enable the development of new compliance enabling technologies.

According the Mr. Barber, an important area for research is to help understand how much exposed wood is acceptable from a fire safety perspective, and how can architectural choices, as well as engineering and material constructions choices influence that answer.

\section{Wood Product Industry Needs: Reducing Fire Hazards: Kuma \\ Sumathipala, American Wood Council, discussed the growing use of wood in the construction industry, due largely to wood's function as a carbon sink. Tall apartment buildings, in particular, are increasingly constructed from wood - with some up to eight stories high. These heights represent new territory for wood building construction and fire resistance requirements; for example, International Building Code (IBC) 2015 mandates the use of fire retardant treated (FRT) wood in exterior wall framing. In some cases, the U.S. market appears reluctant to use FRT wood because of}

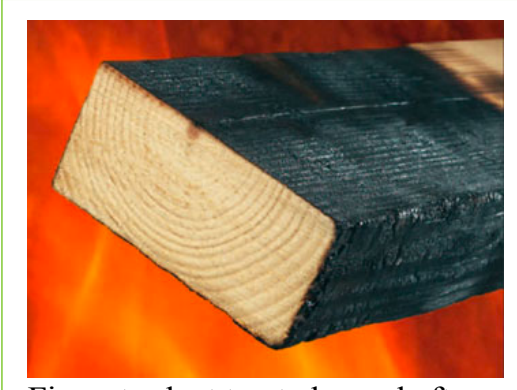

Fire retardant treated wood after exposure to open flames. concerns about its load-bearing capabilities (some linked to interactions between the wood and the metal trusses), the need for automatic sprinkler systems, and a lack of familiarity with the product. Some concealed spaces in buildings may be exempt from the sprinkler requirement, but specifications for this exemption are seldom met in practice due to accessibility requirements. Construction issues requiring research include the use of added chemicals and nanotechnologies, or engineering solutions. Nanotechnology may offer a solution for increasing the fire resistance of FRT wood in exterior wall framing.

Gypsum Basics: Fire Protection: Paul Shipp, United States Gypsum Corporation, discussed calcium sulfate dehydrate $\left(\mathrm{CaSO}_{4} \cdot 2 \mathrm{H}_{2} \mathrm{O}\right)$, commonly known as gypsum. Use of gypsum as a fire-resistant finishing material dates back to the $17^{\text {th }}$ century. It continues to have applications today as a soil supplement, concrete component, emergency road patch, food additive, pharmaceutical additive, and even bone graft material in medical/dental procedures. Abundant quantities of low-cost gypsum occur naturally worldwide. Synthetic gypsum, a byproduct of some industrial processes, is in about $40 \%$ of wallboards in the United States. While gypsum is endlessly recyclable for economic reasons recycling is uncommon. Some believe this could change in the future. Gypsum can be used in elevator shaft wall systems without requiring workers to enter the shaft itself, thus providing a safety benefit. These systems have a two-hour fire rating and are lightweight and versatile, facilitating construction of very tall buildings.

During heating, Gypsum board takes on hemihydrate form $\left(\mathrm{CaSO}_{4} \cdot 1 / 2 \mathrm{H}_{2} \mathrm{O}\right)$ at $212^{\circ} \mathrm{F}\left(100{ }^{\circ} \mathrm{C}\right)$, moves into anhydrite form $\left(\mathrm{CaSO}_{4}\right)$ at about $355^{\circ} \mathrm{F}\left(179{ }^{\circ} \mathrm{C}\right)$, and enters into a solid-solid phase-change reaction at $1500^{\circ} \mathrm{F}\left(816^{\circ}\right.$. At this latter stage, the material undergoes significant volume reduction and remains non-combustible. In summary, gypsum provides high-temperature core cohesion, high-temperature shrinkage, and high-temperature thermal insulation. The specification for special fire-resistant gypsum boards and panels can be found in ASTM C1396. ASTM C1396 requires using ASTM E119 to test fire 
resistance. ASTM E119 is extremely expensive, not easy to use and it isn't clear if the results actually apply to real world performance. Because of these drawbacks and operating this test at a manufacturing sites is impractical, predicative bench scale approaches were developed to efficiently evaluate the key material properties for the fire resistance of gypsum board (ASTM C1795).

Panel Q\&A: Dan Cheney and Tyler Congleton, Boise Cascade, and David Johnston, Vinyl Siding Institute, joined the presenters in addressing comments and questions on durability and other challenges related to fire-resistant materials intended for innovative construction applications. Main points from the discussions are as follows.

- Research and testing has helped the U.S. better understand the fire performance of timber structures. However, opportunities for further research remain. Research and testing could lead to performance benchmarks and design tools that would allow a designer to characterize fire performance, engineer fire protection strategies, and demonstrate safe design.

- Fire tests have shown that delamination can occur in exposed CLT panels. This delamination may result in an increased burning rate for a limited period of time and also can result in an increased char rate for the exposed solid wood as it is instantly exposed to the fire temperatures. An increased understanding of the contribution of exposed timber to room fires has the potential to recognize the contribution, identify if and when delamination might occur, and engineer strategies to meet the specific risks. Further, research also can evaluate the potential for self-extinguishment in exposed timber applications.

- While there is a growing global precedent for tall timber buildings, the building regulatory process in the U.S. has yet to approve the design for a high-rise timber building. The current prescriptive guidance in the International Building $\operatorname{Code}^{6}$ restricts combustible construction to approximately five to six stories, well below the practical limit of approximately eight-plus stories for heavy timber buildings. Approval for a high-rise timber structure would likely require the proposal of an alternative solution to the building code. For this to happen, research studies are needed to provide the comprehensive understanding of timber fire performance, an engineered fire protection strategy, and possibly fire testing, to justify safe design.

- A significant amount of ongoing research is aimed at filling the gaps in knowledge and leading toward a comprehensive understanding of the fire safety challenges in tall timber buildings. Fire testing is a valuable tool to identify fire performance issues and validate analytical tools for fire engineering design and alternative solutions.

- U.S. buildings codes and associated testing standards are different than in Europe - where highrise timber construction is growing rapidly. Research is needed targeting the U.S. market. The research should help us understand the requirements for engineered wood, including interior material finishes, fire ratings for structural frames, fire dynamics (heat release rates and durations), connections, adhesives, encapsulation solutions, and fire-protective coatings for U.S. buildings.

- More fire tests are needed to help guide research and provide the science and engineering basis for regulations. Also, the U.S. needs to develop bench scale tools that predict real scale behavior.

- Building into the 60-plus-story construction realm raises issues with durability, lateral loads on the building, and fire resistance. These issues have been resolved in smaller buildings, but haven't been investigated for these high-rise buildings, globally.

\footnotetext{
${ }^{6}$ International Building Code, International Code Council, Washington, DC, 2012.
} 
- Spray-on gypsum has been used to coat steel and wood but not yet plastics. Gypsum sprays are water-based; solvent-based coatings are also available. Are there applications where the plastic fire performance could be improved using spray-on gypsum?

- Data from real-scale fire tests indicate that fires can be more intense than the ASTM E119 curve. Furthermore, the ASTM E119 time-temperature curve does not show the cooling phase, whereas temperatures for a natural fire tends to decrease after the combustibles become consumed. It is therefore important to understand how well structural integrity is maintained as building materials cool. It was suggested that someone should conduct research to better understand how well ASTM E119 results are with real world scenarios.

\subsection{Advanced Polymers and Composites}

\section{Reducing the Fire Hazard of Materials: Polymers and Composites: Alex Morgan, University of Dayton Research Institute, presented on modern materials and flammability. Although the number of fires has decreased over the last 40 years, they have reached a relatively steady state over the last several years and the dollar cost of fires (when you include fire protections and regulatory compliance activities) has drastically grown.}

Polymers and composites are being used more extensively to deliver diverse benefits to the manufacturer and consumer (e.g.; lower cost, improved and more dynamic performance, longer service life), but this expanded use is changing fire performance and risk. Anytime there is a flammable material, such as most common plastics, there is a risk for fire. This risk can be reduced to a lower level by decreasing the likelihood of the plastic to burn (e.g., using a fire retardant technology) or the impact if it burns (e.g.; use of sprinklers). For example, using a fire retardant in the jacket of an electric wire would have not only stopped flame propagation along the plastic jacket (figure above), but would have prevented the spark from the failing wiring from even igniting the plastic - no ignition, no fire. In vehicles, for example, the increased use of lightweight synthetic carbon-based materials that resist corrosion can increase the fuel load, accelerate flame spread, and significantly reduce time to escape. ${ }^{7}$ This may create a significant life safety problem in mass transit where the release of the toxic combustion gas may result in untenable situations long before flashover.

Some of the current fire tests may pose a significant problem. They are based on fire scenarios that need to be updated to account for more current fuels, usually prescriptive or pass/fail, and often focus on individual components rather than entire systems. The system can be complex and the interactions between the individual components can significantly influence the fire behavior of the individual components. These interactions need to be considered somehow - possible using a test that takes the other components into account (e.g.; multi-component test or a single component test that provides an external exposure to mimic the burning behavior of another component) or a series of tests that when the results are pulled together can provide the required insight.

Future requirements for fire retardant materials will likely be impacted by new regulatory drivers (e.g.; service life requirements and environment issues), and new fire threat from technologies and applications (e.g.; fuel cells, autonomous driving, and 3D printing of parts). Significant research is needed to

\footnotetext{
${ }^{7}$ Use of the Steiner Tunnel for Fire Testing in North America. Marcelo Hirschler, GBH International, USA, Fire and Materials Conference 2011, San Francisco, CA.
} 
understand these new fire scenarios and if the materials and testing methods are adequately capturing the fire-related vulnerabilities.

In terms of fire tests, there needs to be research to better understand the fire and burning behavior in realworld applications and the limitation of the bench scale tests to predict those behaviors. The community needs both screening and predictive bench scale testing tools, but we need to understand to what extent they can be used to screen and to predict. If we are using screening tools to predict real scale behavior we run the risk of making decisions based on inadequate information, which could be costly and dangerous. For example, Cone Calorimeter testing is far less expensive (operation costs, time, amount of material, etc.) than ASTM E84, but if the Cone results aren't a strong predictor then the customer may be better off building rooms / components with E84 rated materials and seeing what really matters (flame spread, heat release, or both) then decide how to best use the Cone or other bench scale tests to identify trends.

What is the role of computational tools? We cannot rely on experimental results alone. Real world fire scenarios are complex. How can an actual fire event in a real fire scenario be modeled correctly, and, can that information be used to develop a more realistic, lower cost, fire safety test? How can models be used to help predict materials that will provide the necessary fire performance when used in a multi-component system (e.g.; predicting what type of barrier fabric is needed to provide sufficient fire safety in furniture). How can we link these two computational models so that the findings from the fire spread in a room be used to guide the development of new compliance enabling technologies and complaint products AND vice versa (the understands gained from modeling the burning behavior of a material and/or product used to predict how it will contribute to fire hazards in a real-world scenarios)? Models must be able to do this in the future to be of value to fire safety scientists.

For fire safety of the future, the market will need new materials and tools that enable the development of these new materials and enhance the use of the existing materials. The limited research and development funds are restrictive to the discovery of new materials. The limited usefulness of the existing testing tools is hindering our ability to identify viable candidates within the existing materials market portfolio. Academia and government organizations, like NIST, should be in a discovery mode. They should conduct research that removes the science and engineering challenges that prevent the development of tools (physical and computational) that may help identify new fire safe materials and chemistries. They should use this new understanding to identify and evaluate new compliance enabling materials and chemistries. Academia and NIST should then transfer the research findings to manufacturers and assist them in developing new commercial products.

\section{A Promising Approach for Reducing the Fire Hazard of Polymers: Yu-Zhong Wang, Sichuan University, presented on} the potential for flame-retardant polyesters. A tremendous amount of polyester is produced - an average of 90 billion metric tonnes (100 billion U.S. tons) each year; however, some intrinsic drawbacks of polyester (e.g.; melt-dripping during fire and loss of mechanical properties after incorporating flame retardants) limits its usefulness in many applications. To address the melt-dripping, the speaker proposed using thermal crosslinking. A series of self-cross-linkable monomers were designed and synthesized, that at high temperatures, crosslinked and further carbonized. The crosslinking increased the polymer melt viscosity at elevated temperatures, resulting in no dripping; and the subsequent carbonization lowered the heat release rates

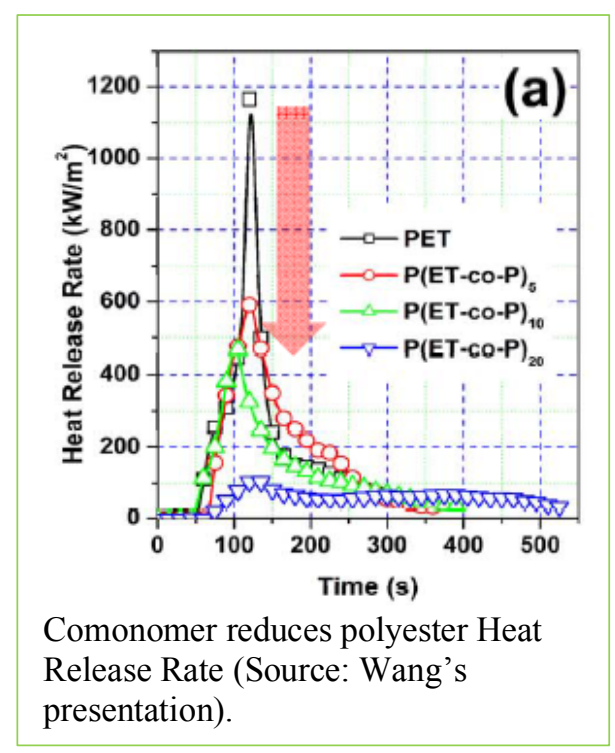


(with higher residue mass over time) to achieve the desirable flame-retardant properties.

In situ micro-fibrillation of the P-containing thermotropic liquid crystalline polymers (PLCPs) is an approach for flame retarding and reinforcing polymeric materials. Different PLCPs were designed and polymerized to meet processing temperatures of different thermoplastic matrices. The in-situ formed micro-fibrils increased mechanical properties, such as tensile strength and modulus. In addition, the flame retardance was enhanced with the P-containing moieties

Panel Q\&A: Yuan Hu, Univ. of Science \& Technology of China, and David Schiraldi, Case Western University, joined the presenters and provided insights on the development of new, fire-resistant polymers and issues of toxicity with these materials. Main points from the discussions are as follows.

- Current fire tests are reactive rather than proactive, usually prescriptive or pass/fail, and often focus on individual components rather than entire systems. Research is needed to provide the baseline understanding that enables the development of tests and to develop the actual tests that can predict how a material will perform in the multi-component system and identify material characteristics essential to the desired burning behavior. This should be accomplished with a combination of experimental and computational tools to predict material burning behavior and understand/identify characteristics essential to the desired burning behavior.

- Current fire standards may not measure toxicity with adequate accuracy - toxicity is dependent on the fire scenario. The test methods need to be re-visited. Development of new polymers faces significant hurdles. Getting a product to market is time-consuming and expensive; it requires working with environmental scientists and chemists to screen materials. A critical issue is developing protocols for reducing the barrier of these hurdles without sacrificing accuracy. Combinatorial screening can help by examining numerous formulations efficiently. It was also mentioned that fire performance is not always the limiting barrier to new material development.

- Throughout the presentations and the panel discussion a common theme was to ensure that in the future laboratory-scale findings of improvements in fire performance are realized in testing at the product scale. As the materials and applications change in the future, so might the fire hazards.

\subsection{Next-Generation Fire Retardants}

Cellulose-Polymer Composites: Douglas Fox, American

University, spoke about using cellulose as an additive to engineer low fire hazard materials and products. Cellulose (fibers and crystal) have multiple benefits that should make it desirable for manufacturers, environmentalist, regulatory agencies, and the general public. Cellulose is environmentally friendly, non-toxic, sustainable, biodegradable, compostable, relatively light and low-density, durable, strong, and insoluble in water. In addition, cellulose serves as a carbon sink if it is not burned or decayed. These are attributes desirable to both environmentalist and the general public alike.

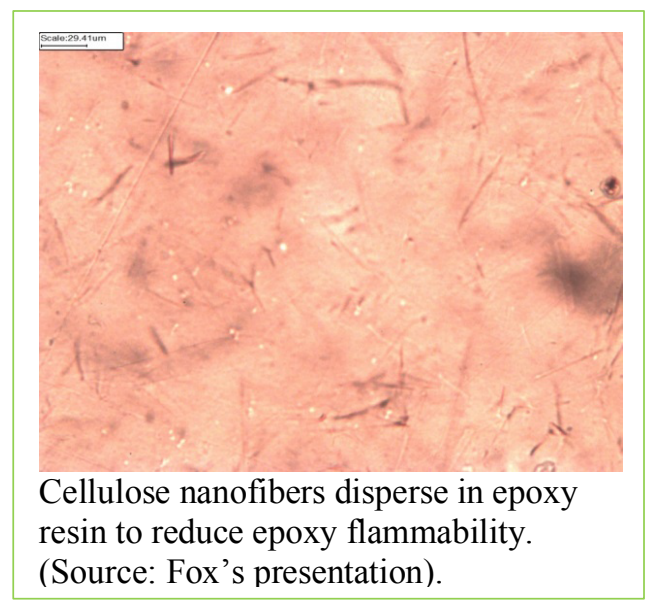

Cellulose has a high modulus, high strength, exhibits low shrinkage and warping, and has a lower abrasion and lower density than most additives. Compared to natural fibers, it has higher thermal stability, less variability, higher strength, and smaller size. Cellulose products come in several forms: microfibers and whiskers are the least expensive; nanofibers offer increased surface area at minimal cost increase; and 
nano-whiskers have been incorporated into epoxy composites to improve reinforcing properties. Cellulose can be functionalized in a manufacturing process, which means it can be tuned to meet specific application needs. These are the types of attributes that should be attractive to manufacturers.

Cellulose can be a fire retardant for plastics. Cellulose has been used as a flame retardant component (through modification with phosphorous containing compounds) providing a charring source, eliminating migration issues, and serving as an oxygen barrier. However, cost-effective methods for improving char yields and adding an acid source are needed to develop cellulose as a standalone fire retardant rather than one component in a fire retardant cocktail. Perhaps the largest obstacles to blending cellulose with polymers are the high-water absorption of cellulose and poor interfacial properties with the polymer matrix. All of these drawbacks might be resolved by attaching the appropriate functional groups to cellulose, but there could be limitations to this approach. For example, adding acid function groups would likely improve cellulose's effectiveness as a fire retardant, but would decrease the interfacial properties if used in a nonpolar polymer matrix. Still, the ability to add functional groups to cellulose provides a handle with which to tailor cellulose in a way that it can be used in a wide variety of polymers and for a wide range of applications.

\section{New and Future Developments in Flame Retardant Epoxy Resins and Composites: Manfred}

Döring, Fraunhofer Institute, discussed the benefits of epoxies and composites, which are commonly used for construction, electronics, and transport because of their light weight, durability, and reliability. Gas- and condensed-phase active flame retardants are often used in carbon-reinforced composites; gasphase retardants may be more efficient in composites. Common technologies include pre-pregging, or impregnating fabric with gas phase flame retardant before cure, and injection. Cone residue formation (charring) of different flame retardants relies on the chemical environment. Flame retardancy increases fracture toughness. Flame retardants also include polymeric and cyclic compounds, including phosphazenes, which have recently become available as non-reactive flame-retardant materials and additives to polymers. Polymeric flame retardants are increasingly preferred and will likely play an increased role in the future because of their low leaching and small influence on material and process parameters. To improve flame retardant properties, researchers are looking into new synergistic or hybrid materials that do not burn.

Panel Q\&A: Charles Olsen, AB Specialty Silicones, joined the presenters and fielded questions on new fire retardants and related challenges. Main points from the discussions are as follows.

- The means of achieving improved fire performance depends on the host polymer and the application in which it is being used. Cellulose is versatile because of the ability to functionalize. With additional research, it has the potential to be used with much wider range of polymer and applications other than conventional fire retardant.

- Coatings may be the most flexible, effective, cost effective, and manufacturing friendly approach to imparting significant fire resistance over a very broad range of materials and applications. However, adhesion can be quite difficult.

- Brominated compounds have been identified as being toxic to people and animals and has therefore, moved industry toward phosphorus compounds. In the future, phosphorous compounds may also face regulatory restrictions

- A participant indicated that novel methyl trichlorosilane based (applied in the gas phase) coatings may increase the smoldering and burning resistance of fabrics. 
- Gas phase treatment of fabrics and precursor raw materials such as chip for oriented strand board and other construction materials can render them significantly resistant to combustion through permanent modification of the cellulose structure.

- "Flame" retardancy is distinct from "fire" retardancy. The latter includes smoldering behavior. Chemical modification to reduce smoldering without the use of phosphorous or bromine compounds is a key goal.

\subsection{Transportation and Infrastructure}

Volpe National Transportation Center Passenger Rail Projects: Mark Gentile, U.S. Department of Transportation, discussed DOT's collaboration with the U.S Army, Coast Guard, Federal Aviation Administration, and Federal Railroad Administration (FRA) to research fire safety.

Gentile discussed NIST Phase III Report - Evacuation of Fire Hazard Analysis Using Full Scale Passenger Rail Car Tests (2004). Major outcomes of the report included a verified fire model for accurate predictions of fire hazards of passenger cars and a small scale test using Cone Calorimeter

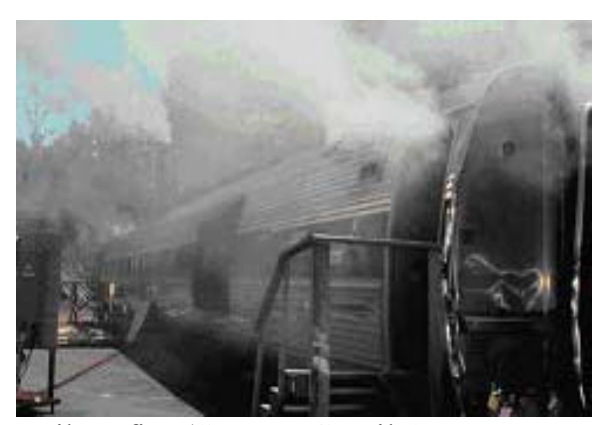

Railcar fire (Source: Gentile's presentation). to screen heat release rate of products used in passenger cars. Volpe Center currently has several new rail project initiatives and would like to partner with the Fire Research division at NIST on these. Gentile recommends NIST could significantly help by do the following.

- verify the calculation of time necessary for passenger egress in an actual emergency

- develop appropriate heat release rate performance criteria (small and full scale test acceptance criteria for materials and component assemblies were not determined in original study)

- quantify the impact of unique fabrics, structural flooring, wall partitions, and wiring and cabling of fire behavior and threat to occupants

- advance computational tools to better understand flame spread and growth as a function of fabrics, structural flooring, wall partitions, and wiring and cabling

\section{Literature Review on Railcar Fire Safety: Brian Lattimer,} Jensen Hughes, discussed the current state of his literature on railcar fire safety. Materials are the single largest factor in fire safety - the largest contributor to the severity of a fire and the largest contributor to eliminating the risk of a fire. Bottom line, if the materials don't burn there isn't a fire.

Fire-related incidents (e.g., Daegu) have prompted considerable research in Europe (resulting, for example, in EN 45545-2), as well as in Korea and Japan. Testing and modeling have led to development of fire performance requirements; the current FRA and National Fire Protection Association (NFPA) 130

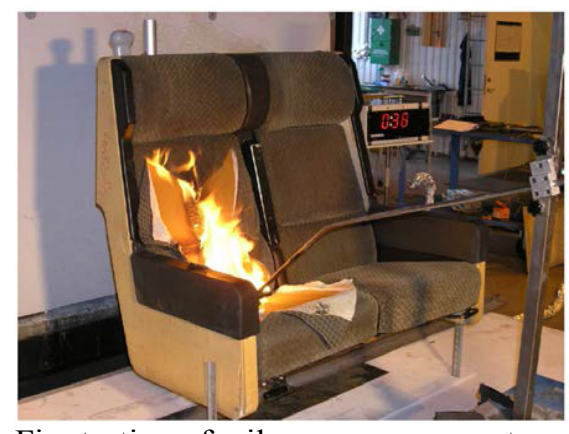

Fire testing of railcar passenger seats (Source: Lattimer's presentation). flammability requirement is based on the ASTM E162 requirement. Globally, the trend is to use heat release rate data from the small-scale cone calorimeter or assembly calorimeter tests to assess material flammability. However, much research is required to determine the basis for the requirement levels 
needed. International codes have additional requirements for toxicity, such as EN 45545-2. U.S. requirements do not typically incorporate toxicity.

Studies abroad have looked at fully developed fires in railcars, and the heat release rates varied widely. Large-scale testing has been conducted on $7 \mathrm{MW}$ to $77 \mathrm{MW}$ fires, highlighting the complexity involved with so many variables (corridor lengths, ventilation systems, etc.). Reduced-scale testing and modeling have shown promise in evaluating the important variables and effects of materials - which can be helpful to manufacturers, who tend to use heat release rates when selecting materials. International research has also touched upon wiring and cables; qualification standards used in railcars, maritime, aviation, and buildings have been reviewed. Char damage length appears to be a better metric than heat release rate to assess cable flammability. Studies have also looked into the fire resistance of flooring assemblies.

Panel Q\&A: Baljinder Kandola, University of Bolton, and Usman Sorathia, U.S. Naval Surface Warfare Center, joined the speakers and provided their perspectives on issues related to materials of construction for infrastructure and transportation, including smoke toxicity and fire retardance. Main points from the discussion are as follows.

- Most of the standards tests are done on uncharged cables. Cable overheating attacks the inner layer of insulation first; fire tests generally heat the cable from outside. The Navy's cable testing methodology addresses toxicity and circuit integrity.

- In general, insulation and cable jacket material are designed for a defined service life. However, there is little or no accelerated aging testing for fire performance, and there is evidence that alumina trihydrate $\left(\mathrm{Al}(\mathrm{OH})_{3}\right)$ loses water (and thus effectiveness) over time. In some cases, cables beyond their service life are not replaced until damaged.

- The timeframe in which different toxic effects may become important depends on the transportation vehicle and on how long people will be exposed to the smoke. Criteria are sometimes developed with the speed of the firefighting group's arrival in mind.

- Smoke toxicity can also affect people downwind of a burning train in a tunnel, so the effectiveness of the smoke control system is an important consideration.

- ISO 16312, Parts 1 and 2, evaluates test methods for determining smoke toxic potency, but found that the then-existing tests were either not particularly appropriate for common fire scenarios and/or that the accuracy of their output data had not been established. More recently NIST Technical Note (TN) 1763 has evaluated new apparatus and variations on exiting apparatus for accuracy in predicting toxic gas production in some real-scale fires.

- Panel reiterated a comment from Dr. Lattimer's presentation - Materials are the single largest factor in fire safety - the largest contributor to the severity of a fire and the largest contributor to eliminating the risk of a fire. Bottom line, if the materials don't burn there isn't a fire.

- Volpe would like to collaborate with NIST on developing new test methods and identifying new compliance enabling technologies (low toxicity, low smoke, etc.) for passenger railcars. 


\section{Fire HaZards - ApPlications ANd Challenges}

After the presentations, the workshop participants were encouraged to envision future scenarios imagining what daily life may be like in five, ten, or more years from now - and the potential fire hazards associated with those future scenarios. Participants visualized buildings, infrastructure, and transportation modes (trains, planes, automobiles) of the future, and what cities and rural areas might look like as modernization progresses. This forward-thinking exercise included future consumer products, such as handheld electronic devices, robots, recycled polymer products; all that could alter peoples' lives in their environments and daily activities.

In these future scenarios, new applications and challenges were identified for the fire community, as well as, applications and challenges that are important now, but may become irrelevant in the future (e.g.; a new technology renders an existing application and associated challenges obsolete). The types of wideranging future applications included, for example, completely electric vehicles or magnetic trains, drones, high-density urban living spaces, and/or virtual reality. In some cases, the participants dove a little deeper and discussed how these changes may impact manufacturers in terms of relevant standards, regulations, and codes. For example, is there a threshold above which the complexity and extent of home monitoring and control devices provide sufficient awareness? With the risk of a fire growing to a hazardous level be sufficiently low so the current regulations may be excessive - increase costs without providing an improvement in fire safety?

\subsection{Applications Requiring Future Fire Reduction Efforts}

Twenty-one applications were identified that required further efforts to reduce their fire hazard. The participants were asked to identify their top two application priorities (most important to address based on their expert opinion). The 18 applications that received votes are shown in Table 3.1; with the entire list of 21 are provided in Table 3.2 to Table 3.5. The "Score" in Table 3.1 to 3.5 reflects the number times that application was marked as a priority. The "Rank" in Table 3.1 (High, Medium, and Low) is based on a line of demarcation in the scoring. The High and Medium priorities were discussed in more in smaller breakout out groups (see Section 3.2 Priority Applications).

Table 3.2 to Table 3.5 describe the challenges, approaches, and unintended consequences (positive and negative) identified for the applications discussed. Applications are organized into four functional areas:

- Building Construction Materials (Total Score =32)

- Interior Furnishings and Electronics (Total Score =17)

- Transportation (Total Score $=6$ )

- Cross-Cutting Fire Protection Technologies (Total Score $=36)$

The total score refers to the total number of votes within that focused area. Future applications of Building Construction Materials cover a wide range and represent some of the highest value of successful fire reduction efforts (see Table 3.2). A major area of interest involves improving the fire resistance of materials used for exposed surfaces in building construction, both exterior and interior. In some cases, enhanced fire resistance is necessitated by innovative concepts for more sustainable building designs, such as lightweight or energy-efficient construction. While these concepts may improve energy efficiency, environmental stewardship, and consumer comfort, they might also create new challenges for fire protection. For example, greater insulation and the use of renewables or energy storage technology in a net-zero home could alter fire behavior and spread, necessitating changes to fire codes. 
In Interior Furnishings and Electronics, upholstered furniture continues to be a major area of interest (see Table 3.3). Fabrics and flexible polyurethane foam used in furniture have variable degrees of fire resistance (dependent on the construction, etc.). Other technologies are available to meet flammability standards, such as coatings and fire-resistant barriers. Due to concerns over the possible health hazard of chemical fire retardant additives, the state of California eliminated the part of TB 117 (i.e., flaming ignition) for which the FR additives had been used. ${ }^{8}$ In addition to upholstered furniture, the increase in wireless connections and electronics in homes and commercial buildings may pose new fire hazards because of an increased amount of remotely controlled appliances and an increased amount of electrical connections/loads.

In the Transportation area, the applications of greatest interest are passenger railcars, buses, airplanes, and cars (see Table 3.4). (Aerospace applications and shipping were not addressed.) While many existing standards govern flammability in transportation equipment, continued modernization creates a need to reevaluate, improve, and potentially develop new, less-flammable materials that reduce smoke and increase fire resistance overall. Other progressive transportation concepts (e.g., positive train control, allelectric vehicles) are creating new paradigms that require another look at fire hazards and ways to improve fire protection. Plug-in electric vehicles (EVs), for example, have been involved in fires related to their advanced lithium-ion batteries. As a result, some carmakers publish a guide for first responders on the proper handling of crashes involving electric-drive vehicles and steps to safely disable EV batteries and other high-voltage systems. ${ }^{9}$

Cross-Cutting Fire Protection Technologies include new engineering and chemistry approaches that enable compliance with regulations and codes (call these approaches compliance enabling technologies) (see Table 3.5). These have the ability to impact an extremely wide range of applications. Development of new compliance enabling technologies is one of the most important areas identified for further study. A key challenge in developing fire retardants technologies and low flammability materials is toxicity; retardants must be effective at reducing fire hazards (and meet flammability standards) while minimizing ecologic impacts on human health and the environment. Another important area is measuring the fire performance of a product over time. When products are new, they may meet all standards for fire protection, but not enough is known about how performance degrades over time or with use.

Many advanced materials offer possible applications in fire protection and fire hazard reduction. Fiberreinforced composites (e.g., hybrid organic-inorganics) could have numerous applications in construction and transportation, as well as in other areas. Fire-resistant polymers and composites could be engineered to generate less smoke and provide greater fire resistance.

\footnotetext{
8 "Furniture firms shun flame retardants but some toxic couches still for sale," Chicago Tribune, October 3, 2016. www.chicagotribune.com/news/watchdog/

${ }^{9}$ General Motors (2011-01-19). "Detroit First Responders Get Electric Vehicle Safety Training". General Motors News. Retrieved 10-5-2016.
} 


\section{Application Focus Area}

\begin{tabular}{|c|c|c|c|c|c|c|}
\hline \multicolumn{3}{|c|}{ Table 3.1. Future Applications Identified } & \multicolumn{4}{|c|}{ Application Focus Area } \\
\hline Rank & Score & Application & $\begin{array}{c}\text { Building } \\
\text { Construction } \\
\text { Materials }\end{array}$ & $\begin{array}{l}\text { Interior } \\
\text { Furnishings } \\
\quad \text { and } \\
\text { Electronics }\end{array}$ & Transportation & $\begin{array}{l}\text { Cross } \\
\text { Cutting Fire } \\
\text { Protection } \\
\text { Technologies }\end{array}$ \\
\hline \multirow{4}{*}{$\begin{array}{l}\text { High } \\
\text { Priority }\end{array}$} & 13 & Upholstered furniture & & $\mathrm{x}$ & & \\
\hline & 11 & $\begin{array}{l}\text { Resistance to exterior fire } \\
\text { exposure }\end{array}$ & $\mathrm{x}$ & & & \\
\hline & 11 & $\begin{array}{l}\text { Non-toxic, viable, reactive, } \\
\text { fire retardants to meet } \\
\text { flammability standards }\end{array}$ & & & & $\mathrm{x}$ \\
\hline & 10 & $\begin{array}{l}\text { Fire performance over } \\
\text { product lifetime }\end{array}$ & & & & $\mathrm{x}$ \\
\hline \multirow{6}{*}{$\begin{array}{l}\text { Medium } \\
\text { Priority }\end{array}$} & 6 & Lightweight construction & $\mathrm{x}$ & & & \\
\hline & 6 & Exposed wood surfaces & $\mathrm{x}$ & & & \\
\hline & 5 & $\begin{array}{l}\text { Fiber-reinforced composites } \\
\text { in transportation and } \\
\text { construction }\end{array}$ & & & & $\mathrm{x}$ \\
\hline & 5 & $\begin{array}{l}\text { New technology for fire } \\
\text { protection }\end{array}$ & & & & $\mathrm{x}$ \\
\hline & 5 & $\begin{array}{l}\text { Fire-resistant } \\
\text { polymers/composites with } \\
\text { lower smoke (soot) } \\
\text { generation and fire } \\
\text { resistance }\end{array}$ & & & & $\mathrm{x}$ \\
\hline & 4 & $\begin{array}{l}\text { Passenger rail, cars, } \\
\text { locomotives }\end{array}$ & & & $\mathrm{x}$ & \\
\hline \multirow{8}{*}{$\begin{array}{l}\text { Low } \\
\text { Priority }\end{array}$} & 3 & $\begin{array}{l}\text { Interconnected wireless } \\
\text { appliances (home } \\
\text { automation) }\end{array}$ & & $\mathrm{x}$ & & \\
\hline & 3 & $\begin{array}{l}\text { Zero-net energy homes, } \\
\text { energy efficient construction }\end{array}$ & $\mathrm{x}$ & & & \\
\hline & 3 & $\begin{array}{l}\text { Encapsulation of mass } \\
\text { timber construction } \\
\text { elements }\end{array}$ & $\mathrm{x}$ & & & \\
\hline & 2 & $\begin{array}{l}\text { Increased building code } \\
\text { requirements for fire } \\
\text { performance }\end{array}$ & $\mathrm{x}$ & & & \\
\hline & 1 & Electric vehicles & & & $\mathrm{x}$ & \\
\hline & 1 & Positive train control & & & $\mathrm{x}$ & \\
\hline & 1 & Flexible interior materials & $\mathrm{x}$ & & & \\
\hline & 1 & $3 \mathrm{D}$ printing in every home & & $\mathrm{x}$ & & \\
\hline \multicolumn{3}{|c|}{ Total votes in each focus area } & 32 & 17 & 6 & 36 \\
\hline
\end{tabular}


Table 3.2. Applications Identified for Future Fire Reduction Efforts:

Construction Materials

\begin{tabular}{|c|c|c|c|c|}
\hline Score & Applications & Challenges & Possible Approaches & $\begin{array}{c}\text { Undesirable } \\
\text { Consequences }\end{array}$ \\
\hline 11 & $\begin{array}{l}\text { Resistance to } \\
\text { exterior fire } \\
\text { exposure }\end{array}$ & $\begin{array}{l}\text { Maintaining existing } \\
\text { desirable properties } \\
\text { (including architectural) and } \\
\text { economic value of exterior } \\
\text { building materials while } \\
\text { increasing resistance to fire }\end{array}$ & $\begin{array}{l}\text { Identify vulnerable areas of } \\
\text { building envelopes } \\
\text { - Focus on defending vulnerable } \\
\text { locations } \\
\text { - Develop prescriptive solutions } \\
\text { and construction assemblies }\end{array}$ & $\begin{array}{l}\text { Minimum house spacing } \\
\text { affects - land use } \\
\text { Changes making land } \\
\text { buildable/unbuildable } \\
\text { - Code/zoning changes } \\
\text { making existing } \\
\text { structures or } \\
\text { communities obsolete } \\
\text { Insurance/water issues }\end{array}$ \\
\hline 6 & $\begin{array}{l}\text { Lightweight } \\
\text { Construction }\end{array}$ & $\begin{array}{l}\text { - Reducing vulnerability to } \\
\text { ignition and flame spread } \\
\text { - Metrology for separation } \\
\text { and recycling } \\
\text { - Methods to predict } \\
\text { performance (e.g.; } \\
\text { delamination in a fire) }\end{array}$ & $\begin{array}{l}\text { Develop sandwich, core, and } \\
\text { hybrid materials } \\
\text { - Develop new less flammable } \\
\text { adhesives for laminated wood } \\
\text { - Gain international cooperation } \\
\text { - Develop bench scale to predict } \\
\text { full scale performance }\end{array}$ & $\begin{array}{l}\text { - Need for recycling } \\
\text { - Changes in materials } \\
\text { leading to other delays } \\
\text { (insufficient supply) } \\
\text { - Pushback from "legacy" } \\
\text { materials manufacturers }\end{array}$ \\
\hline 6 & $\begin{array}{l}\text { Exposed wood } \\
\text { surfaces }\end{array}$ & $\begin{array}{l}\text { - Appeal of exposed wood to } \\
\text { architects } \\
\text { - Controlling surface flame } \\
\text { spread }\end{array}$ & $\begin{array}{l}\text { Develop fire-retardant nanotech- } \\
\text { coatings for exposed wood } \\
\text { surfaces }\end{array}$ & $\begin{array}{l}\text { Possible VOCs from } \\
\text { wood adhesives and } \\
\text { coatings } \\
\text { - Exposed wood no longer } \\
\text { in fashion; disposal } \\
\text { becomes an issue }\end{array}$ \\
\hline 3 & $\begin{array}{l}\text { Zero-net energy } \\
\text { homes; energy- } \\
\text { efficient } \\
\text { construction }\end{array}$ & $\begin{array}{l}\text { - Meeting the needs of solar } \\
\text { and wind power collection } \\
\text { and storage with low } \\
\text { flammability materials } \\
\text { - Risk of increased fire } \\
\text { hazards and decline in } \\
\text { structural integrity }\end{array}$ & $\begin{array}{l}\text { - Develop standards and } \\
\text { performance requirements } \\
\text { - Train fire departments } \\
\text { - Evaluate test methods in context } \\
\text { of new dynamics } \\
\text { - Determine if an increase of } \\
\text { insulation or air barriers alters fire } \\
\text { behavior }\end{array}$ & $\begin{array}{l}\text { - Change in fire dynamics } \\
\text { - Inadequacy of current } \\
\text { engineering design tools } \\
\text { - Mismatched test methods } \\
\text { and fire codes }\end{array}$ \\
\hline 3 & $\begin{array}{l}\text { Encapsulation in } \\
\text { mass timber } \\
\text { construction }\end{array}$ & $\begin{array}{l}\text { Defining benefits under } \\
\text { real-fire scenarios (how to } \\
\text { calculate benefit of } \\
\text { encapsulation) }\end{array}$ & $\begin{array}{l}\text { - Develop non-standard design fire } \\
\text { scenarios } \\
\text { - Perform testing under those } \\
\text { scenarios }\end{array}$ & $\begin{array}{l}\text { Selected fire scenarios } \\
\text { and testing too limited in } \\
\text { scope }\end{array}$ \\
\hline 2 & $\begin{array}{l}\text { Increased } \\
\text { building code } \\
\text { requirements for } \\
\text { fire performance }\end{array}$ & $\begin{array}{l}\text { - Need for research on } \\
\text { Intumescent technology (for } \\
\text { performance of wooden I- } \\
\text { beams) } \\
\text { - Active fire suppression }\end{array}$ & $\begin{array}{l}\text { - Launch sustained effort to } \\
\text { improve existing protection } \\
\text { methods, which are insufficient }\end{array}$ & $\begin{array}{l}\text { - Smoke toxicity } \\
\text { - Recyclability } \\
\text { - Price of product }\end{array}$ \\
\hline 1 & $\begin{array}{l}\text { Flexible interior } \\
\text { materials }\end{array}$ & $\begin{array}{l}\text { High rate of flame spread } \\
\text { on large areas with } \\
\text { flammable surfaces }\end{array}$ & $\begin{array}{l}\text { - Limit flammability of fabrics and } \\
\text { foams via regulations }\end{array}$ & $\begin{array}{l}\text { - Smoke toxicity } \\
\text { - Recyclability } \\
\text { - Price of Product }\end{array}$ \\
\hline 0 & $\begin{array}{l}\text { New building } \\
\text { materials, } \\
\text { shapes, and } \\
\text { combinations }\end{array}$ & $\begin{array}{l}\text { Mismatch of tests and fire } \\
\text { codes (for everything } \\
\text { needing protection) }\end{array}$ & $\begin{array}{l}\text { Develop inorganic/hybrid } \\
\text { thermoplastics (long-term) } \\
\text { Support full-scale test-backed } \\
\text { regulations and better models }\end{array}$ & - Increased fire loss \\
\hline 0 & $\begin{array}{l}\text { Carbon fiber for } \\
\text { building tall } \\
\text { structures }\end{array}$ & $\begin{array}{l}\text { - Materials that resist } 1500^{\circ} \mathrm{C} \\
\text { and retain required strength } \\
\text { - New materials that enhance } \\
\text { fire resistance }\end{array}$ & $\begin{array}{l}\text { Conduct tests on fire resistance } \\
\text { and durability over time } \\
\text { - Understand conflicts with other } \\
\text { products }\end{array}$ & $\begin{array}{l}\text { Excessive fire protection } \\
\text { in the building }\end{array}$ \\
\hline 0 & $\begin{array}{l}\text { Insulation for } \\
\text { high-rise } \\
\text { buildings } \\
\text { (Class A) }\end{array}$ & $\begin{array}{l}\text { Combining low thermal } \\
\text { conductivity/calorific } \\
\text { value/density with high fire } \\
\text { resistance }\end{array}$ & $\begin{array}{l}\text { Set goals to achieve thermal } \\
\text { conductivity }<0.035 \mathrm{~W} / \mathrm{m}^{\circ} \mathrm{C} \text {; } \\
\text { calorific value }<2 \mathrm{MJ} / \mathrm{m}^{2}\end{array}$ & $\begin{array}{l}\text { - Increased cost of } \\
\text { material }\end{array}$ \\
\hline
\end{tabular}




\section{Table 3.3. Applications Identified for Future Fire Reduction Efforts:} Interior Furnishings and Electronics

\begin{tabular}{|c|c|c|c|c|}
\hline Score & Applications & Challenges & Possible Approaches & $\begin{array}{l}\text { Undesirable } \\
\text { Consequences }\end{array}$ \\
\hline 13 & $\begin{array}{l}\text { Upholstered } \\
\text { furniture }\end{array}$ & $\begin{array}{l}\text { Small smoldering fires that } \\
\text { rapidly become large fires } \\
\text { - Flaming vs. smoldering } \\
\text { ignition-existing } \\
\text { approaches can't always } \\
\text { handle both } \\
\text { Less-flammable materials } \\
\text { that do not compromise } \\
\text { comfort and aesthetics }\end{array}$ & $\begin{array}{l}\text { Develop component tests and } \\
\text { standards } \\
\text { - Conduct risk analyses } \\
\text { - Utilize inorganic flexible } \\
\text { polymers }\end{array}$ & $\begin{array}{l}\text { - Price of product } \\
\text { - Impact on comfort and } \\
\text { aesthetics } \\
\text { - Consumer resistance } \\
\text { - Manufacturer resistance } \\
\text { - Environment/Health/ Safety } \\
\text { (EHS) problems } \\
\text { - Increase in fire losses }\end{array}$ \\
\hline 3 & $\begin{array}{l}\text { Interconnected } \\
\text { wireless } \\
\text { appliances (home } \\
\text { automation) }\end{array}$ & $\begin{array}{l}\text { - Increasing volume of } \\
\text { plastics and electronics in } \\
\text { homes } \\
\text { - Recyclability } \\
\text { - Increased electricity demand }\end{array}$ & $\begin{array}{l}\text { Develop very low-toxicity } \\
\text { plastics or plastics that burn } \\
\text { cleanly, i.e., with less toxic } \\
\text { smoke } \\
\text { - Explore/define ways to } \\
\text { recycle products }\end{array}$ & $\begin{array}{l}\text { - New demands on landfills } \\
\text { - Issues with burning or } \\
\text { incinerating waste }\end{array}$ \\
\hline 1 & $\begin{array}{l}\text { 3D printing in } \\
\text { every home }\end{array}$ & $\begin{array}{l}\text { - Fire risk of microscale, self- } \\
\text { assembling nano-composites } \\
\text { - Large increase in polymer } \\
\text { content of homes (increased } \\
\text { fuel load) } \\
\text { - New polymers for } \\
\text { feedstock, with unknown } \\
\text { fire behavior }\end{array}$ & $\begin{array}{l}\text { - Evaluate materials (fire } \\
\text { hazards) via testing } \\
\text { - Enable on-site quality control }\end{array}$ & $\begin{array}{l}\text { - Inability to recycle } \\
\text { - Recycling of residues } \\
\text { - Potential for dangerous } \\
\text { physical degradation over } \\
\text { time }\end{array}$ \\
\hline
\end{tabular}

Table 3.4. Applications Identified for Future Fire Reduction Efforts: Transportation

\begin{tabular}{|c|c|c|c|c|}
\hline Score & Applications & Challenges & Possible Approaches & $\begin{array}{l}\text { Undesirable } \\
\text { Consequences }\end{array}$ \\
\hline 4 & $\begin{array}{l}\text { Passenger rail, } \\
\text { cars, locomotives }\end{array}$ & $\begin{array}{l}\text { Reduced flammability } \\
\text { materials that do not } \\
\text { compromise passenger } \\
\text { comfort }\end{array}$ & $\begin{array}{l}\text { - Achieve fire and smoke } \\
\text { reduction } \\
\text { - Eliminate fire and smoke }\end{array}$ & $\begin{array}{l}\text { - Passenger discomfort } \\
\text { - Post-service disposal }\end{array}$ \\
\hline 1 & $\begin{array}{l}\text { Positive train } \\
\text { control }\end{array}$ & $\begin{array}{l}\text { - Risks posed by electrical } \\
\text { fires, total system failure, } \\
\text { burden on train power } \\
\text { systems }\end{array}$ & $\begin{array}{l}\text { - Increase testing } \\
\text { - Create redundant system } \\
\text { backups } \\
\text { - Develop common software } \\
\text { and hardware }\end{array}$ & $\begin{array}{l}\text { - Limited human intervention } \\
\text { and operation, loss of jobs } \\
\text { - Security and safety concerns }\end{array}$ \\
\hline 1 & Electric vehicles & $\begin{array}{l}\text { - Overheating of power } \\
\text { electronics } \\
\text { - Fires caused by battery } \\
\text { failure } \\
\text { - First-responder safety }\end{array}$ & $\begin{array}{l}\text { Explore gallium nitride, } \\
\text { silicon carbide, diamond } \\
\text { materials using high- } \\
\text { temperature stress test rigs }\end{array}$ & - Competition for rare materials \\
\hline
\end{tabular}


Table 3.5. Applications Identified for Future Fire Reduction Efforts: Cross-Cutting Fire Technologies

\section{\begin{tabular}{l|l|l|l|l|} 
Score & Applications & Barriers/Challenges & Possible Approaches & $\begin{array}{c}\text { Undesirable } \\
\text { Consequences }\end{array}$
\end{tabular}}

\section{Fire Retardants and Protection Technologies}

\begin{tabular}{|c|c|c|c|c|}
\hline 11 & $\begin{array}{l}\text { Non-toxic, viable, } \\
\text { reactive, flame } \\
\text { retardants to meet } \\
\text { flammability } \\
\text { standards }\end{array}$ & $\begin{array}{l}\text { Understanding what } \\
\text { technology is available } \\
\text { Data on fire-resistant } \\
\text { properties for multiple } \\
\text { applications } \\
\text { - Negative perceptions }\end{array}$ & $\begin{array}{l}\text { Create fire retardant tests for } \\
\text { toxicology and flammability } \\
\text { standards } \\
\text { - Identify needed standards } \\
\text { Create modes for information } \\
\text { sharing }\end{array}$ & $\begin{array}{l}\text { Other fire resistant } \\
\text { treatments (different } \\
\text { markets) } \\
\text { - Pushback on new } \\
\text { technology }\end{array}$ \\
\hline 10 & $\begin{array}{l}\text { Fire performance } \\
\text { over product } \\
\text { lifetime }\end{array}$ & $\begin{array}{l}\text { Lack of fire performance } \\
\text { measurements for products } \\
\text { as they age } \\
\text { Need to better understand } \\
\text { fire performance over time }\end{array}$ & $\begin{array}{l}\text { Develop accelerated aging } \\
\text { procedure for fire tests }\end{array}$ & $\begin{array}{l}\text { Potential reduction in } \\
\text { available qualified } \\
\text { materials for fire } \\
\text { resistance }\end{array}$ \\
\hline 5 & $\begin{array}{l}\text { New technology } \\
\text { for fire protection }\end{array}$ & $\begin{array}{l}\text { - Low-toxicity fire retardant } \\
\text { coatings } \\
\text { - 3D (sandwich) materials } \\
\text { - Encapsulation mechanics }\end{array}$ & $\begin{array}{l}\text { Evaluate toxicity (materials, } \\
\text { additives, measurements, test } \\
\text { methods, mechanisms) } \\
\text { - Evaluate fire retardant/toxic } \\
\text { properties after aging }\end{array}$ & $\begin{array}{l}\text { - Price of product } \\
\text { - Recycling }\end{array}$ \\
\hline \multicolumn{5}{|c|}{ Materials } \\
\hline 5 & $\begin{array}{l}\text { Fiber-reinforced } \\
\text { composites in } \\
\text { transportation and } \\
\text { construction }\end{array}$ & $\begin{array}{l}\text { - Hybrid organic-inorganic } \\
\text { materials } \\
\text { - Materials that use ceramics } \\
\text { in bulk/surface coatings } \\
\text { - Critical properties/ physics } \\
\text { and needed computational } \\
\text { tools }\end{array}$ & $\begin{array}{l}\text { - Develop small-scale tests for } \\
\text { screening materials } \\
\text { - Pursue methods for sensing } \\
\text { thermal decomposition during } \\
\text { use } \\
\text { - Understand math/physics for } \\
\text { scaling and testing } \\
\text { - Identify ways to scale up } \\
\text { existing small tests }\end{array}$ & $\begin{array}{l}\text { - Flammability of } \\
\text { resin/thermoplastic } \\
\text { polymers } \\
\text { - Softening of resin at } \\
\text { glass transition } \\
\text { temperature }\end{array}$ \\
\hline 5 & $\begin{array}{l}\text { Fire resistant } \\
\text { polymers/ } \\
\text { composites with } \\
\text { lower smoke (soot) } \\
\text { generation }\end{array}$ & $\begin{array}{l}\text { - Understanding what } \\
\text { technology is available } \\
\text { - Data on fire resistant } \\
\text { properties and smoke } \\
\text { generation for multiple } \\
\text { polymers } \\
\text { - Scaling-up from lab to } \\
\text { industrial production }\end{array}$ & $\begin{array}{l}\text { - Explore synergetic } \\
\text { combination of fire resistance } \\
\text { technologies } \\
\text { - Research nano-dispersed } \\
\text { catalysis } \\
\text { - Develop new polymers with } \\
\text { intrinsically low soot } \\
\text { generation }\end{array}$ & $\begin{array}{l}\text { - Promotion of systems } \\
\text { which generate nano- } \\
\text { sized soot particles, } \\
\text { reducing opacity but } \\
\text { increasing health } \\
\text { hazard }\end{array}$ \\
\hline
\end{tabular}




\subsection{Research Needs and Implementation Plans for Priority Applications}

After evaluating and prioritizing these approaches and applications, the highest and medium priority elements were identified for further analysis. For each of these priority areas, small groups of participants developed action plans that describe the scope of the application work area; the key challenges; major steps to be undertaken; major milestones and targets; the benefits of undertaking the work; and potential stakeholders. Possible undesirable consequences that could occur as a result of addressing the problems identified were also discussed.

Four of the priority applications were addressed by all three groups.

- Residential Upholstered Furniture $($ Score $=13)$

- $\quad$ Resistance to Exterior Fire Exposure $($ Score $=11)$

- Non-toxic / Sustainable Fire Retardants $($ Score $=11)$

- Fire Performance Over Product Lifetime $($ Score $=10)$

The following additional applications were also reviewed.

- High Rise Buildings (2 groups) - Combination of Lightweight Construction (Score =6) and Insulation of High Rise Buildings (Score $=0$ )

- $\quad$ Exposed Wood Surfaces (1 group, Score =5)

- Fiber Reinforced Composites in Transportation and Construction (1 group, Score $=5)$

In a subsequent analysis of the combined action plans, trends or commonalities were identified. For example, the combined responses to "Resistance to Exterior Fire Exposure" clearly had two different focuses: Testing Protocol or Methods, and New Solutions. In other areas, topic areas were not sufficiently distinct, and could not be combined. The reorganized topic areas were then further grouped into 3 general categories, as listed below.

\section{Building Construction Applications}

- Exterior: Testing Protocols - Develop tests to evaluate ignition sources and fire performance of new structures (Figure 3.1)

- Exterior: New Solutions - Identify the exterior surfaces most vulnerable to fire and address those vulnerabilities using novel materials and systems (Figure 3.2). This is essentially a request to evaluate technologies that enable compliance with tests developed in Figure 3.1.

- Exterior: WUI Residential Building Vulnerabilities - Develop an understanding of ember ignition vulnerabilities for WUI residential homes and potential fire spread within the interior (Figure 3.3)

- Exposed Wood Surfaces - Tailor fire protection solutions to preserve the appearance of internal and external wood (natural, non-structural, and structural), based on specific uses (Figure 3.4)

- Building Insulation Tests and Protocols for High-Rise Buildings - Enable more sustainable fireresistant insulation by developing cost-effective tests that reflect real fire scenarios (Figure 3.5)

- Hybrid Insulation Materials for High-Rise Buildings - Develop advanced materials and performance tests for high-rise insulation with low heat conductivity/flammability (Figure 3.6)

\section{Building Interior Applications}

- Residential Upholstered Furniture Test Scenarios and Materials - Design bench-scale test to predict full-scale effects/heat release rates for diverse materials and design scenarios (Figure 3.7) 
- Residential Upholstered Furniture Performance Models - Develop model to predict fire performance of upholstered furniture and facilitate reduction of fire hazards (Figure 3.8)

- Interior Construction: Service Life - Study interiors (including concealed spaces) and the factors affecting fire performance over time (Figure 3.9)

\section{Cross-Cutting}

- Engineering Safe Fire Retardants: Improved Tests and Technologies - Develop clear performance tests to accelerate manufacturer use of safe flame retardant treatments (Figure 3.10)

- Engineering Safe Fire Retardants: New and More Flexible Technologies - Develop new tools and chemical classes to provide non-toxic fire resistance in a wide range of materials and applications (Figure 3.11)

- Aging Protocols and Models for Fire Performance over Product Lifetime - Analyze real or artificially aged materials to assess changes affecting performance or toxicity (Figure 3.12)

- New Fiber-Reinforced Composites - Assess required material parameters, develop new test methods, and design and fabricate new composites with desired properties (Figure 3.13)

Groups were asked to describe the problem or challenge and identify the necessary tasks to arrive at a solution, on a short ( $<5$ years), medium (6 years to 10 years) and long ( $>10$ years) term. For each task, they were asked to identify a measureable milestone. They were also asked to identify any efficiencies or barriers for full implementation, and identify any undesirable consequences, such as a significant increase in the cost.

For the four highest priority areas, all three groups provided input. Three additional priority areas were analyzed by one or two groups. Since the priority areas have been reorganized for this section, each one includes a note regarding the number of groups that contributed to that analysis. 


\subsubsection{Building Construction Applications}

\section{Figure 3.1. Priority APPliCATION - Building ConstruCtion APPlications EXTerior: Testing Protocols}

DESCRIPTION: Better testing protocols are needed to assess various types of exterior fire exposure, whether from embers falling from a wildfire, sparks entering through a window, or radiant/flame spread from an adjacent structure or wildfire. Many proposed solutions are untested, and existing and new structures require different solutions. The fire performance of suggested improvements needs to be qualified, and new test methods are needed to support performance measurement and design.

*Figure 3.1 suggests developing standardized test methods (and facilitate incorporation into regulations and codes) for exterior products, with a heavy focus on WUI communities. Figure 3.2 suggests developing and helping to implement compliance technologies and products. Figure 3.3 focuses on ember ignition for WUI residential homes.

READINESS LEVEL: Ready to use; Ideas - need work

Probability of Realization: $>50 \%$

\section{MAJOR TASKS}

\section{TARGETS}

OTHER CONSIDERATIONS

- Build matrix ranking vulnerabilities

- Test different ignition sources (ember vs. open flame vs. smolder) and use to model/predict or better understand the physics

- Develop standardized performance tests for new and existing structures

- New testing methods and compliant technologies in the market

- Alter panel assembly test to better correlate to real-fire scenario cladding with less vulnerable alternatives

- Expand protocols as new materials emerge

- Updated test protocols

\section{Technology Transfer}

- Acceptance by industry

- Demonstrated viability and relevance of tests

UNDESIRABLE CONSEQUENCES

- Increased cost

\section{STAKEHOLders \& POTENTIAL ROLES}

\section{BENEFITS/IMPACTS}

- Industry: woods products, cementitious siding, roofing, fire retardant companies, building industry

- Fire Service: International Association of Fire Chiefs, International Association of Fire Fighters, National Volunteer Fire Council

- First Responders: US Fire Responders Association

- Universities: University of Maryland, Worchester Polytechnic Institute, University of Edinburgh, California Polytechnic State University, San Diego State University, Wichita State University

- Trade Groups: Vinyl Institute, American Wood Council

- Standards Committees/SDOs: International Code CouncilInternational Wildland-Urban Interface Code, National Fire Protection Association (1141-4), American Society for Testing and Materials (E2886), Underwriters Laboratory

- Government: US Forest Service, Bureau of Land Management, US Fish and Wildland (DOI), US National Parks Service

- National Labs: Missoula Group, Forest Products Lab, National Institute of Standards and Technology
High Fire Losses (if not pursued): Greater property losses; California and Texas today are examples

Medium Fire Losses (if successful): Large fires are still risky, but major improvements are possible

Low Environment and Human Health (if not pursued): Big risk is loss of property and, for large fires, the environmental impacts. There is unknown potential impact from inhalation during a fire and from by-products (after the fire is gone) due to the fire suppressants and burnt materials

Low Environment and Human Health (if successful): Unknown

Medium Cost of Meeting Fire Performance with Future Approaches: May be high, but should be lower than increase in insurance or loss of property 


\section{Figure 3.2. PRiORity APPLICATION - BUILDING CONSTRUCTION APPLICATIONS EXTERIOR: NEW SOLUTIONS}

DESCRIPTION: The challenge is to increase the fire resistance of building exteriors while maintaining flexibility, service, aesthetics, practicality, and value. The approach is to identify vulnerabilities in the envelope, develop new solutions and technologies that will improve fire resistance, and then address these in the building codes. The focus is on the most vulnerable locations, i.e., sources of ignition.

*Figure 3.2 suggests developing and helping to implement materials and engineering technologies that enable compliance with the standards, regulations, and codes that are described in Figure 3.1.

READINESS LEVEL: Ideas - need work

Probability of Realization: $>50 \%$

\section{MAJOR TASKS}

\section{TARGETS}

OTHER CONSIDERATIONS

- Identify vulnerable areas on structures. Identify the primary ignition sources (i.e., lawn furniture)

- Identify ignition mechanisms

- Prioritize based on risk of exposure and size of potential loses

- Identify and evaluate current solutions, and identify those not currently tested for new and existing structures

- Identify and evaluate new technologies for new and existing structure

- Develop new materials specific to the problem (i.e., intumescent paints, fire-resistant coatings, etc.)

- Identify and evaluate nonmaterial-based engineering solutions (i.e., exterior sprinklers)

- For existing structures, develop an easy-to-apply and inexpensive technology - such as gel/protein/waterbased foam for emergency application

- Provide stakeholders an understanding of the effectiveness of existing technologies

- New materials and FR technologies (specifically coatings) for vulnerabilities, such as roof, and decking

- Fire suppression systems for exterior

- Determination of effectiveness and shortterm durability of foam sprays (ideally several days)

Technology Transfer

- Code and zoning changes making structures or communities obsolete

UNDESIRABLE CONSEQUENCES

- Insurance or water issues

- New technologies in the market

- Modify building code according to findings

- Updated building codes

- N/A

- N/A

\section{STAKeHOLders \& POTENTIAL ROLES}

- Industry: woods products, cementitious siding, roofing, fire retardant companies, building industry

- Fire Service: International Association of Fire Chiefs, International Association of Fire Fighters, National Volunteer Fire Council

- First Responders: US Fire Responders Association

- Universities: University of Maryland, Worchester Polytechnic Institute, University of Edinburgh, California Polytechnic State University, San Diego State University, Wichita State University

- Trade Groups: Vinyl Institute, American Wood Council

- Standards Committees/SDOs: International Code Council- International WildlandUrban Interface Code, National Fire Protection Association (1141-4), American Society for Testing and Materials (E2886), Underwriters Laboratory

- Government: US Forest Service, Bureau of Land Management, US Fish and Wildland (DOI), US National Parks Service

- National Labs: Missoula Group, Forest Products Lab, National Institute of Standards and Technology

\section{BENEFITS/IMPACTS}

High Fire Losses (if not pursued): Potential increases

Medium Fire Losses (if successful): Potential decreases

High Environment and Human Health (if not pursued): Impacts due to fire loss

Medium Environment and Human Health (if successful): Potential for less impact

Medium Cost of Meeting Fire Performance with Future Approaches: Use of costeffective approaches 


\section{Figure 3.3. Priority APPliCATION - BUILding ConstruCtion APPliCATions EXTERIOR: WUI RESIDENTIAL BUILDING VULNERABILITIES}

DESCRIPTION: Residential buildings are exposed to fire from external sources, including wildland interface and urban/suburban building-to-building exposures. There is a need to study the similarities and differences between these two types of fire exposure and assess how they affect potential solutions. Solutions need to preserve consumer choice, aesthetic preferences, construction practicality, and economics. The focus is primarily on small residential rather than large or commercial structures.

*Figure 3.3 suggests developing an understanding of ember ignition vulnerabilities for WUI residential homes and potential fire spread within the interior.

READINESS LEVEL: Ideas - path not clear

Probability of ReAlization: $>50 \%$

\section{MAJOR TASKS}

TARGETS

OTHER CONSIDERATIONS

- Assess and quantify similarities and differences in radiant exposure and ember attack

- Investigate post-WUI fires to understand what is actually happening during real fires

- Match observers/data gathering to locations: "storm chasers"

- Identify and evaluate critical factors/weaknesses leading to fire and spread to building interior

- Develop solutions that are practical/economical and allow for design flexibility and aesthetics

- Popularize solutions; work to incorporate solutions into building codes and standard construction practices
- Reduced losses, particularly those due to fire spread to the interior of the building

- Validated factors in fire spread and potential solutions

- Standardized levels of performance, independent of materials types and construction types

- Prescriptive solutions that can be implemented by builders and adapted for different house designs without engineering

- Monitor effectiveness and success, societal changes

Technology Transfer

- Standard construction practices, building codes

\section{UNDESIRABLE CONSEQUENCES}

- Reduction in consumer choice, dissatisfaction (needs to be addressed through projects)

\section{STAKeHOLders \& POTENTIAL ROLeS}

\section{BENEFITS/IMPACTS}

- Industry: woods products, cementitious siding, roofing, fire retardant companies, building industry

- Fire Service: International Association of Fire Chiefs, International Association of Fire Fighters, National Volunteer Fire Council

- First Responders: US Fire Responders Association

- Universities: University of Maryland, Worchester Polytechnic Institute, University of Edinburgh, California Polytechnic State University, San Diego State University, Wichita State University

- Trade Groups: Vinyl Institute, American Wood Council

- Standards Committees/SDOs: International Code CouncilInternational Wildland-Urban Interface Code, National Fire Protection Association (1141-4), American Society for Testing and Materials (E2886), Underwriters Laboratory

- Government: US Forest Service, Bureau of Land Management, US Fish and Wildland (DOI), US National Parks Service

- National Labs: Missoula Group, Forest Products Lab, National Institute of Standards and Technology
Medium Fire Losses (if not pursued): Potential for widespread losses

Low Fire Losses (if successful): Reduced losses to exposed buildings

Low Environment and Human Health (if not pursued): Human health/safety not particularly affected by exterior fire

Low Environment and Human Health (if successful): N/A

Medium Cost of Meeting Fire Performance with Future Approaches: Need to work toward low-cost solutions 


\section{Figure 3.4. Priority APPLiCATION - BUILDing CONSTRUCTION APPLiCATIONS EXPOSED WOOD SURFACES (INTERIOR AND EXTERIOR)}

DESCRIPTION: Exposed wood surfaces are increasingly popular in construction for aesthetics but can pose new fire hazards. There is a need to reduce the flammability of wood products that are exposed (not behind walls or non-flammable materials) to protect the occupants of inside spaces as well as external wooden structures (structural, non-structural, and natural [plants/trees]) for property protection. The approach is to develop cost-effective, sustainable solutions that provide fire protection yet preserve the appearance in the application. Solutions may vary by end use because of the different types of wood surfaces needing protection (e.g., structural wood, decks, trees, etc.)

*Figure 3.4 discusses exposed wood (interior and exterior), where a subset would apply to WUI topics in Figure 3.1 and Figure 3.2. To simplify the discussion here, we've removed comments about the exterior wood that were already addressed in Figure 3.1 or Figure 3.2 .

READINESS LEVEL: Ideas - need work Probability of Realization: $>50 \%$

\section{MAJOR TASKS}

- Identify, develop, and evaluate standardized test methods and environmentally friendly compliance technologies improving the fire resistance of interior wood and exterior wood products (both for structural and aesthetics)

- Also include foliage surface protection, but post-fire environmental decomposition of surface protection is required

\section{TARGETS}

- Existing tests to evaluate reaction to fire, as relevant to the end-use application (SBI, ASTM E84)

- Solutions that are environmentally benign and meet cost, performance, and aesthetic requirements

- Utilization of tool proposed in Figure 3.9 NonToxic Viable Reactive Flame Retardant Priority Application

- Established industry/government/academic consortium working on the problem together in a sustained, focused, multi-year effort

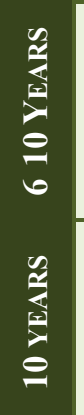

- None

- N/A

- None

- N/A

\section{OTHER CONSIDERATIONS}

\section{TeChNOLOGY Transfer}

- Solutions developed presented to regulatory agencies for potential code changes

- Technologies developed are available to all consortium members for industrial commercialization

- Consideration of coating approaches as fire protection solutions for temporary construction; conduct follow-on study

\section{Undesirable ConSEQUenCES}

- Health effects of sanding/ refinishing of surface protective coatings are unknown and need to be addressed

\section{STAKeHOLDERS \& POTENTIAL ROLES}

- Industry: wood products industry, paint/coating manufacturers, construction industries, fire and flame retardant industry

- Fire Service: International Association of Fire Chiefs, International Association of Fire Fighters, National Volunteer Fire Council

- First Responders: US Fire Responders Association

- Universities: University of Dayton Research Institute

- Trade Groups: American Wood Council

- Standards Committees/SDOs: International Code Council, National Fire Protection Association, American Society for Testing and Materials, International Standards Organization, Underwriters Laboratory

- Government: TBD

- National Labs: Forest Products Laboratory, National Institute of Standards and Technology

\section{BENEFITS/IMPACTS}

Medium Fire Losses (if not pursued): Depends upon whether architects or existing building codes prevail over exposed wood surfaces. High impact if architects prevail; medium impact if existing building codes prevail

Medium Fire Losses (if successful): Able to meet architectural/aesthetic needs while preserving fire safety

Medium Environment and Human Health (if not pursued): Fire losses unchanged vs. where they are today

High Environment and Human Health (if successful): More use of sustainable building materials that meet fire protection requirements; increased human happiness for building occupants

Medium Cost of Meeting Fire Performance with Future Approaches: If successful, medium impact—if suitable costs are obtained 


\section{FigURE 3.5. PRIORITY APPLICATION - BUILDING CONSTRUCTION APPLICATIONS BUILDING INSULATION TESTS AND PROTOCOLS FOR High RISE BUILDINGS}

DESCRIPTION: Upgraded test methods are needed to support development of fire-resistant, energy-efficient, sustainable insulation materials for high-rise buildings. The suggested approach is to develop a cost-effective alternative to NFPA 255, Standard Method of Test of Surface Burning Characteristics of Building Materials. The new test should lead to the commercialization of lower-cost and more sustainable, energy-efficient fire-resistant insulation materials for high-rise buildings. The challenges include developing a test that captures real fire scenarios (e.g., fire spread, system) and identifying failure mechanisms.

*Figure 3.5 suggests developing standardized test methods (and facilitate incorporation into regulations and codes) of insulation for high rise buildings. Also, it suggests recommending compliant products from the existing product portfolio. Figure 3.6 suggests developing and helping to implement new compliance technologies and products for the tests described in Figure 3.5.

READINESS LEVEL: Ideas stage - needs further work

Probability of Realization: $>50 \%$

\section{MAJOR TASKS}

TARGETS

OTHER CONSIDERATIONS

- Understand failure mechanisms on insulation at full scale; consult with experts in field

- Develop and evaluate computational tools and standardized tests methods (multi-scale) Use computational tools to develop

- Evaluate strategies for existing building inventory

- Enable changes to existing building codes and regulations

- Recommend compliant technologies and products.

- Elimination of high-rise building fires using sustainable fire resistant materials and building structures

- Potential uses in residential buildings

- Distribution and use of accepted test method
TECHNOLOGY TRANSFER

- Supply chain sources for new materials

Undesirable Consequences

- Residential use

- N/A

\section{$\gamma$}

STAKeHOLDERS \& POTENTIAL ROLES

\section{$>$

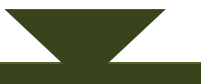

Fire Service: International Association of Fire Chiefs, International Association of Fire Fighters, National Volunteer Fire Council

- First Responders: US Fire Responders Association

- Universities: TBD

- Trade Groups: TBD

- Standards Committees/SDOs: International Code Council, National Fire Protection Association, American Society for Testing and Materials, International Standards Organization, Underwriters Laboratory

- Government: TBD

- National Labs: National Institute of Standards and Technology
High

High

N/A Environment and Human Health (if not pursued):

\section{BENEFITS/IMPACTS}

Fire Losses (if not pursued): Experimental use of products is just beginning. N/A.

N/A Environment and Human Health (if successful): N/A.

Low Cost of Meeting Fire Performance with Future Approaches: Goal is lower costs. 


\section{FiguRE 3.6. PRIORITY APPLICATION - BUILDING CONSTRUCTION APPLICATIONS HYBRID INSULATION MATERIALS FOR HIGH RISE BUILDINGS}

DESCRIPTION: Low thermal conductivity materials with low flammability are needed for insulation applications. New hybrid materials with reduced flammability are one approach. Existing insulating materials are a main source of flame spread, especially in high-rise buildings. A test method is also required to determine how to reduce the fire hazard without affecting performance.

*Figure 3.6 suggests developing and helping to implement materials and engineering technologies that enable compliance with the standards, regulations, and codes that are described in Figure 3.4.

READINESS LEVEL: Ideas - path not clear

Probability of Realization: $<50 \%$

\section{MAJOR TASKS}

- Identify and evaluate performance targets and requirements

- Identify and evaluate a bench-scale methods for assessing performance

- Identify, develop, and evaluate compliance technologies and potentially compliant products

- Assess product life performance

- Enable the development of appropriate building codes

- Enable manufacturing of compliant products Affordable
being used

\section{TARGETS}

OTHER CONSIDERATIONS

- Reduced HRR (heat release rate), flame spread, and smoke production

- Enabling of toxicologically benign fire retardant solutions

- No major effect on cost or the density and thermal conductivity of

0
0
0
0
0
0
0
0
0
0

- $\quad$ N/A the insulation material

- Affordable and complaint insulation

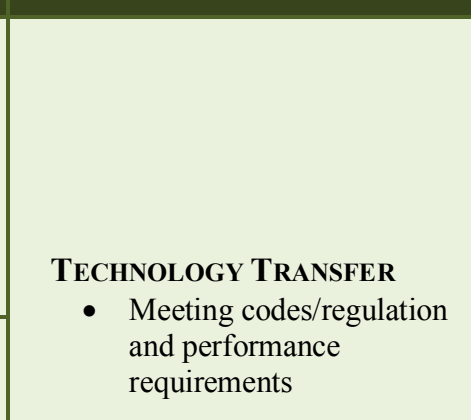

Undesirable ConSEQUenCES

- Increased cost of material

\section{STAKeHOLDERS \& POTENTIAL ROLES}

- Industry: flame and fire retardant industry, construction industry, insulation manufacturers

- Fire Service: International Association of Fire Chiefs, International Association of Fire Fighters, National Volunteer Fire Council

- First Responders: US Fire Responders Association

- Universities: TBD

- Trade Groups: TBD

- Standards Committees/SDOs: International Code Council, National Fire Protection Association, American Society for Testing and Materials, International Standards Organization, Underwriters Laboratory

- Government: TBD

- National Labs: National Institute of Standards and Technology

\section{BENEFITS/IMPACTS}

Medium Fire Losses (if not pursued): Constantly rising, e.g., at wildland urban interface (WUI)

Medium Fire Losses (if successful): Potential decrease

Medium Environment and Human Health (if not pursued): Continued impacts of toxic FRs

High Environment and Human Health (if successful): Benign FRs would decrease environmental, health, and safety (EHS) issues

Medium Cost of Meeting Fire Performance with Future Approaches: Moderate cost alternatives 


\subsection{Building Interior Applications}

\section{FigURE 3.7. PRIORITY APPLICATION - BUILDING INTERIOR APPLICATIONS RESIDENTIAL UPHOLSTERED FURNITURE (RUF) TEST SCENARIOS AND MATERIALS}

DESCRIPTION: The diverse geometries, materials, and designs of residential upholstered furniture (RUF) make it hard to predict burning behavior and assess the fire threat. Although upholstered furniture fires result in more fatalities than any other residential fire in the United States, no regulations (or standards) currently exist for bench-scale tests. Tests are needed to predict full-scale effects from the bench scale and to facilitate the comparison of furniture materials based on heat release rates.

*Figure 3.7 suggests developing multi-scale RUF flammability tests for screening and regulations, and developing compliance enabling technologies and materials. Figure 3.8 suggests developing computational tools that help manufactures and retails select components that will comply with the regulations.

READINESS LEVEL: Ideas need work and path not clear

Probability OF REAlization: $>50 \%$

\section{MAJOR TASKS}

TARGETS

OTHER

CONSIDERATIONS

- Identify, develop, and evaluate "real fire" test scenarios for smoldering and open flame ignition of RUF

- Identify, develop, and evaluate bench-scale tests that predict "real scale" burning behavior of RUF - could be used in regulations and/or to accelerate development of RUF and subcomponent designs with lower flammability

- Identify, develop, and evaluate bench-scale tests for assessing the burning behavior components - help manufacturers develop new materials and technologies

- Develop and validate a clear understanding of the burning behavior of RUF and the fire threat to homes, along with performance metrics to be used for regulations - consider metrics such as HRR, room temperature, and smoke

- Identify, develop, and evaluate computational models to drive "real fire" test scenario and explore/test real fire scenarios

- Evaluate relevant British Standard test(s) to predict real fire test performance

- Enable the development of new testing, and fire regulations for RUF based on the test methods described above.

- Identify, develop, and evaluate new materials and technologies that enable compliance with above mentioned tests and regulations - must be environmental, health, and fire safe

- $\quad$ Provide support and know-how for new standards/regulations and test methods

- Provide recommendations on the ability of existing materials and technologies to meet the above metrics and market needs.

- Identify, develop, and evaluate replacements for foam and/or eliminate foam contribution to RUF burning.

- Identify, develop, and evaluate EHS compliant, fire resistant and performance based technologies and solutions to remove foam

- Standardized tests that predict real scale and associated regulations are developed that reduce the fire threat associated with RUF

- Standardized tests for developing new materials and components

- New materials and technologies in the market that enable compliance with regulations

- Developed/established regulations and standards to determine upholstered furniture flammability and enable comparison of new materials to existing materials
Technology Transfer

- Wide distribution of test protocols

\section{UNDESIRABLE}

\section{Consequences}

- Other RUF properties could be diminished (e.g., comfort)

- Push-back by manufacturers 
- Industry: Furniture and component manufacturers, fire retardant manufacturer

- Fire Service: International Association of Fire Chiefs, International Association of Fire Fighters, National Volunteer Fire Council

- First Responders: US Fire Responders Association

- Universities: TBD

- Trade Groups: American furniture manufacturers, Center for the Polyurethane Industries, American Chemistry Council, Polyurethane Foam Association, Upholstered Furniture Action Council, Bureau of Electronic and Appliance Repair, Home Furnishings and Thermal Insulation

- Standards Committees/SDOs: National Fire Protection Association (e.g., Fire Test Committee), American Society for Testing and Materials (e.g.; E05.15), International Standards Organization, Underwriters Laboratory

- Government: Consumer Products Safety Commission

- National Labs: National Institute of Standards and Technology
High

Fire Losses (if not pursued): High fire losses, more flammable materials/FB117

High Fire Losses (if successful): Lower fire losses and loss of life

High Environment and Human Health (if not pursued): Already high

High Environment and Human Health (if successful): Reduces effects on human health

Medium Cost of Meeting Fire Performance with Future Approaches: Resources to solve/implement at low cost 


\section{FIgURE 3.8. PRIORITY APPLICATION - BUILDING INTERIOR APPLICATIONS Residential Upholstered Furniture PerformanCe Models}

DESCRIPTION: Furniture that burns quickly and intensely increases the risk of room flashover and endangers building occupants. New tests and models are needed to accurately predict furniture flammability and help manufacturers design products that catch fire less readily and burn more slowly, potentially reducing the loss of lives and property.

*Figure 3.8 suggests developing computational tools that help manufactures and retails select components that will comply with the regulations described in Figure 3.7.

READINESS LEVEL: Ideas - need work Probability Of Realization: $>50 \%$

- Conduct parametric testing of Residential Upholstered Furniture (RUF) to identify the physical and fire behavior properties of components that affect the heat release rate of the final product.

- Conduct survey of past work

- Survey or develop component property tests

- Identify, develop, and evaluate "model" to predict product performance based on property test results

- Conduct tests to estimate degree of prediction validity

- Identification of prime component properties affecting RUF flammability

- Manufacturers' tool for identifying furniture that poses a significantly reduced fire hazard

\section{TECHNOLOGY TRANSFER}

- Use of tests and results by furniture manufacturers

\section{UNDESIRABLE CONSEQUENCES}

- Manufacturer resistance

- Some upholstery materials made obsolete as a result

\section{STAKEHOLDERS \& POTENTIAL ROLES}

- Industry: Furniture and component manufacturers, fire retardant manufacturer

- Fire Service: International Association of Fire Chiefs, International Association of Fire Fighters, National Volunteer Fire Council

- First Responders: US Fire Responders Association

- Universities: TBD

- Trade Groups: American furniture manufacturers, Center for the Polyurethane Industries, American Chemistry Council, Polyurethane Foam Association, Upholstered Furniture Action Council, Bureau of Electronic and Appliance Repair, Home Furnishings and Thermal Insulation

- Standards Committees/SDOs: National Fire Protection Association (e.g., Fire Test Committee), American Society for Testing and Materials (e.g.; E05.15), International Standards Organization, Underwriters Laboratory

- Government: Consumer Products Safety Commission

- National Labs: National Institute of Standards and Technology

\section{BENEFITS/IMPACTS}

Medium Fire Losses (if not pursued): Similar losses continue

Medium Fire Losses (if successful): Could decrease losses via better design of new fabrics

Medium Environment and Human Health (if not pursued): Similar impacts continue

Medium Environment and Human Health (if successful): Could improve EHS performance through avoidance of poorperforming fabrics

Medium Cost of Meeting Fire Performance with Future Approaches: Helps to reduce costs associated with fire losses 


\section{Figure 3.9. PRIORITY APPLICATION - BUILDING INTERIOR APPLICATIONS INTERIOR CONSTRUCTION: SERVICE LIFE}

DESCRIPTION: Existing ASTM and ISO methods predict the fire performance of exterior products (outside structure, exposed to the elements) over time, but no methods exist to project the fire performance of products designed for internal use (inside structure, either behind walls or exposed to interior environments). There is a need to understand what phenomena these materials are exposed to, how to test against those phenomena, and what the performance metrics should be.

*Figure 3.9 suggests developing an understanding of how the fire performance changes over time for products and materials used inside buildings.

READINESS LEVEL: Ideas - need work

Probability of Realization: $>50 \%$

\section{MAJOR TASKS}

- Identify and evaluate typical inside exposures and the resulting condition of the materials and products for the duration of the exposure

- Identify, develop, and evaluate methods for accelerating the exposure to achieve similar material and product characteristics

- Commence long-term internal aging studies

- Identify, develop, and evaluate computational tools to interpolate and extrapolate the product performance to other exposure durations and types

- New standard test methods that academia and industry can use

\section{TECHNOLOGY TRANSFER}

- Interact with ASTM, ISO, and relevant trade and professional organizations.

- Hold conferences and publish peer reviewed results to engage wider community

- Continue long-term internal aging studies and

- Continued validation and improvement of internal validation/comparison against accelerated tests accelerated aging tools that academia and industry can use

UNDESIRABLE CONSEQUENCES

- None

- Continued validation and improvement of internal accelerated aging tools that academia and industry can use

\section{STAKEHOLDERS \& POTENTIAL ROLES}

- Industry: flame and fire retardant industry, construction industry

- Fire Service: International Association of Fire Chiefs, International Association of Fire Fighters, National Volunteer Fire Council

- First Responders: US Fire Responders Association

- Universities: Duke, North Carolina State, Case Western University, Lille University of Science and Technology, Univ. of Dayton Research Institute

- Trade Groups: American furniture manufacturers, Center for the Polyurethane Industries, American Chemistry Council, Polyurethane Foam Association, Upholstered Furniture Action Council, Bureau of Electronic and Appliance Repair, Home Furnishings and Thermal Insulation

- Standards Committees/SDOs: National Fire Protection Association, American Society for Testing and Materials, International Standards Organization, Underwriters Laboratory

- Government: TBD

- National Labs: National Institute of Standards and Technology

\section{BENEFITS/IMPACTS}

Medium Fire Losses (if not pursued): Situation remains as is

Low-High Fire Losses (if successful): A decrease in fire losses should occur.

Low Environment and Human Health (if not pursued): Purpose is to ensure materials work as they should over time and develop knowledge to properly determine impact

Medium Environment and Human Health (if successful): Validating materials can be used for a long time could reduce waste from buildings

Low Cost of Meeting Fire Performance with Future Approaches: Makes existing material durability known, does not change fire test costs 


\subsubsection{Cross-Cutting Approaches}

\section{Figure 3.10. Priority ApPlication - Cross Cutting ENGINEERING SAFE FIRE RETARDANTS: IMPROVED TESTS AND TECHNOLOGIES}

DESCRIPTION: The ban on an increasing number of effective flame-retardant chemicals is changing current flame retardant treatments. Equally effective new products need to be developed that are non-toxic and environmentally safe. There is a need to accelerate the commercialization and implementation of sustainable flame retardant technology with improved fire safety (e.g., consumer products and construction materials). Challenges include the absence of fast and inexpensive compliance EHS test methods and negative public perception of flame retardant (FR) chemicals (e.g., all FR halogens are bad). In addition, FR developers lack a full understanding of FR mechanisms. The use of polymers that are inherently resistant to fire is a promising approach. Such polymers can be either used as the end product or added as a flame/fire retardant-whether incorporated in the matrix or applied as a part of a coating or sealant.

*Figure 3.10 suggests developing fundamental understanding of FR mechanisms (along with associated tools and methods) that will accelerate development of EHS compliant FR technologies.

REAdiness LeVEL: Ideas - need work (EHS \& FR Test); Path not clear (materials) ProbabILITY OF REALIZATION: >50 \% \begin{tabular}{|l|l|l} 
MAJOR TASKS & TARgETS & OTHER CONSIDERATIONS
\end{tabular}

- Identify, develop, and evaluate product end use database to determine polymer classes and current flammability needs (e.g., baby clothing, furniture, wood); expand as needed.

- Begin with current flammability standards and tailor them to better fit end uses.

- Identify, develop, and evaluate open flame tests to augment current standards.

- Identify, develop, and evaluate clear, performance-based test standards and metrics (including toxicity) for FR manufacturers that correlate with real life performance

- Identify, develop, and evaluate (fast) tools and methods to understand the performance mechanisms of fire resistance

- Identify, develop, and evaluate closer connections between fire/flame retardant scientists and environmental and toxicology departments

- Identify and evaluate emerging technology (e.g., bio-derived FR and coatings); screen for performance and EHS compliance

- Use rapid durability measurement (mechanical, water/leaching) to assess environmental concerns

- Continue simultaneous tailoring of existing standards to better fit end uses and polymer classes

- Identify and evaluate applications and demonstrate EHS and FR effectiveness in real tests

- Evaluate toxicity of new technologies

- Identify, develop, and evaluate written changes to the fire code to include new technologies (e.g., exceptions for material or for meeting extended fire resistance times)
- Database to readily identify polymer classes and to focus research, allowing some flexibility

- Identification of industry stakeholders and get them involved

- Standard FR tests used correctly

- Toxicology tests and target based on discussions with collaborators

- Achievement of accelerated development of FRs

- Proven FR technology that passes toxicity tests

- Satisfying other performance targets, including mechanical, durability, EHS, and fire reduction, etc.

- Cost effective FR technology that passes performance, toxicological, and durability tests and has achieved broad regulatory acceptance (for construction)
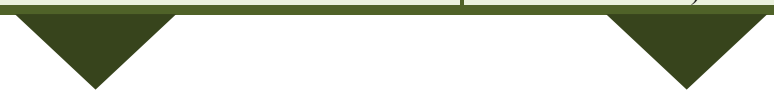

\section{Technology Transfer}

- $\quad$ EHS and FR approvals for marketing

\section{UNDESIRABLE ConSEQUenCES}

- Cost of final product goes up

- "Consumer happy"

- Reduction in performance attributes and service life 


\section{STAKEHOLDERS \& POTENTIAL ROLES}

- Industry: fire and flame retardant industries and their customers

- Fire Service: Industry: International Association of Fire Chiefs, International Association of Fire Fighters, National Volunteer Fire Council

- First Responders: US Fire Responders Association Universities: Case Western University, Lille University of Science and Technology, Univ. of Dayton Research Institute

- Trade Groups: TBD

- Standards Committees/SDOs: National Fire Protection Association, American Society for Testing and Materials, International Standards Organization, Underwriters Laboratory

- Government: Consumer Products Safety Commission, Environmental Protection Agency

- National Labs: Bundesanstalt für Materialforschung und -prüfung (BAM), National Institute of Standards and Technology

\section{BENEFITS/IMPACTS}

High Fire Losses (if not pursued): Current FR under scrutiny; ban of FR increases fire loss risk

High Fire Losses (if successful): Fire losses decrease

Medium Environment and Human Health (if not pursued): Toxic FRs are being phased out

High Environment and Human Health (if successful): New technology includes environmentally friendly approaches

Low Cost of Meeting Fire Performance with Future Approaches: If successful, it will be low; some technologies may be higher, R\&D may be higher, but cost to manufacturers once developed are low 


\section{Figure 3.11. Priority APPlication - Cross CutTing} Engineering SAFE Fire Retardants: NeW AND MORE FleXIble TeChNOlogies

DESCRIPTION: Existing flame retardant chemical classes are being phased out due to environmental issues, public perception, and government regulation. There is a need to develop new general chemical classes and approaches that can work on a wide range of materials (textiles, wood, plastics, etc.) and have a low environmental footprint. Challenges include clearly understanding the specific toxicological implications of diverse chemical classes and structures - a prerequisite for the development of accurate screening tools.

*Figure 3.11 suggests developing more flexible and universal FRs - deliver targeted fire resistance for a broader range of applications and materials - that don't compromise environment and human health.

READINESS LEVEL: Ideas - need work

Probability of Realization: $>50 \%$

\section{MAJOR TASKS}

- Identify, develop, and evaluate new FR approaches that are chemically compatible with and provide inherent fire resistance for a very broad range of material compositions

- Identify, develop, and evaluate new FR approaches that are easily tailorable to provide a broad range of fire behaviors in the materials

- Identify, develop, and evaluate a flame-retardant application tool by chemical structure for specific material class/ chemistry; tool would be virtual in that chemical structure would be put into the tool/model; output parameter would be the potential materials with which it could be used

- Identify, develop, and evaluate toxicology screening tools by chemical structure rather than extensive experimental work; tools should be virtual with ability to draw chemical structure and give an idea of potential toxicology (does not include post-fire toxicity, but rather the toxicity of the pre-fire chemical itself)

- Identify, develop, and evaluate environmental footprint screening tools based on chemical structure rather than extensive experimental work; tools should be virtual so that we can draw a chemical structure and have some idea of the potential footprint (include total life cycle analysis)

- Identify, develop, and evaluate a flame retardant application tool by chemical structure for specific fire safety applications; tool would be virtual in that chemical structure would be entered into tool $/$ model, and output would be the applications it could be used with and the resulting fire retardation parameters

- Easy-to-use tool to provide a materials scientist, chemist, or engineer (nonenvironmental scientist) with some prediction of the environmental footprint (includes total life cycle analysis)
TEChNOLOGY Transfer

- Will require sustained, focused effort and funding to be successful; requires partnership between fire scientists, chemists, and toxicologists/environmental scientists

- Must be an open-source model and universally accessible

\section{UNDESIRABLE CONSEQUENCES}

- None

- Modify/update as needed

- Continuous improvement

\section{STAKeHOLDERS \& POTENTIAL ROLES}

\section{BENEFITS/IMPACTS}

- Industry: fire and flame retardant industries and their customers

- Fire Service: Industry: International Association of Fire Chiefs, International Association of Fire Fighters, National Volunteer Fire Council

- First Responders: US Fire Responders Association

- Universities: Case Western University, Lille University of Science and Technology, Univ. of Dayton Research Institute

- Trade Groups: TBD
Medium Fire Losses (if not pursued): As FR are deselected, some materials will become more flammable

High Fire Losses (if successful): Would be able to have publically acceptable fire safety solutions

High Environment and Human Health (if not pursued): Increased fire damage/loss, and resulting negative impacts to environment and health 
- Standards Committees/SDOs: National Fire Protection Association, American Society for Testing and Materials, International Standards Organization

- Government: Consumer Products Safety Commission, Environmental Protection Agency

- National Labs: Bundesanstalt für Materialforschung und -prüfung (BAM), National Institute of Standards and Technology
High Environment and Human Health (if successful): Increased fire damage/loss, and resulting positive impacts to environment and health

Medium Cost of Meeting Fire Performance with Future Approaches: Some high initial costs, but costs of new products will drop over time 


\section{Figure 3.12. Priority APPliCATiOn - Cross Cutting SERViCe LifE: NeW Methods, MOdels, AND MATERIAls}

DESCRIPTION: Currently, fire performance is a property assessed on a new product - there isn't a fire performance requirement as the product goes through typical end use wear and tear. The approach is to focus on products prominent in fire losses, estimate the degree of degradation of fire behavior due to wear and aging, and assess any degradation in terms of the product lifetimes currently set by consumer demand and/or manufacturer choice. A challenge is the lack of protocols for accelerated aging of fire-retardant products.

*Figure 3.12 suggests providing the science and engineering basis that establishes fire requirements over the service life of a product, methods to evaluate a materials compliance and result in new technologies and evaluate new technologies that comply with these requirements.

READINESS LEVEL: Ideas - path not clear

MAJOR TASKS
Probability of Realization: $<50 \%$

\section{TARGETS}

- Develop a prioritized list of products with service life concerns overlapping with fire loses.

- Gather information (field and literature) on typical service life conditions and factors (e.g.; weathering, and wear and tear)

- Evaluate real products from the field to determine deterioration as a function of time - primarily fire performance

- Identify, develop, and evaluate methods for accelerating the exposure to achieve similar material and product characteristics

- For products with existing standard accelerated aging tests, obtain before and after specimens and perform fire tests - use this to help in the prioritization list and identify gaps in tests, regulations, and materials/product performance

- For product without existing standard accelerated aging tests, test new products and retest after crude accelerated aging protocol

- Assess potential changes to materials: molecular changes, leaching of flame retardant chemicals, etc.

- Evaluate impacts on fire performance vs. toxicity (changes may potentially be in opposite directions)

- Identify, develop, and evaluate computational tools to interpolate and extrapolate the product performance to other exposure durations and types

- Develop and conduct tests to validate models and aging protocols

- Study potential for mitigating or reversing aging effects

- Validate aging protocols

- Conduct long-term studies of aging

- Examine naturally aged and worn products versus same products whose age and wear were accelerated

- Defined accelerated aging protocols

- Potential compounding effects that do not represent real-world aging

- Comparative effects of different temperature/ light/ moisture/time combinations, wear, and chemical exposure on the product vs. real world

- Tests to assess bioavailability of toxins potentially released

- Standardized accelerated aging protocols, tests for retention of fire performance

- Incorporated protocols/tests into standard methods, e.g., ASTM

\section{STAKEHOLDERS \& POTENTIAL ROLES}

- Industry: flame and fire retardant industry and end product manufacturers

- Fire Service: International Association of Fire Chiefs, International Association of Fire Fighters, National Volunteer Fire Council

- First Responders: US Fire Responders Association

\section{BENEFITS/IMPACTS}

High

Fire Losses (if not pursued):

Unknown; depends on effects of aging discovered 
- Universities: Case Western University, Lille University of Science and Technology, Univ. of Dayton Research Institute

- Trade Groups: American Chemistry Council, industry aligned groups will be determined later

- Standards Committees/SDOs: National Fire Protection Association, American Society for Testing and Materials, International Standards Organization, Underwriters Laboratory

- Government: TBD

- National Labs: National Institute of Standards and Technology, Bundesanstalt für Materialforschung und -prüfung (BAM)
High Fire Losses (if successful): Dependent on effects of aging but could be significant

N/A Environment and Human Health (if not pursued): N/A.

N/A Environment and Human Health (if successful): N/A.

Low Cost of Meeting Fire Performance with Future Approaches: Little impact on cost 


\section{Figure 3.13. Priority APPliCATion - Cross Cutting NEW FIBER REINFORCED COMPOSITES}

DESCRIPTION: Transportation vehicles and buildings need to retain their physical integrity during fires to protect occupants and first responders. Fiber reinforced composites offer a promising route to new materials of construction that maintain their physical integrity during and after direct exposure to fire and high heat. The key challenge is to design and fabricate new composites with the desired properties. The approach involves assessing the required material parameters and developing appropriate test methods. This addresses a principal advanced materials concern for transportation vehicles and also has important application to building structural systems.

*Figure 3.13 suggests developing new composites that maintain physical integrity during and after a fire.

READINESS LEVEL: Ideas - need work

\section{MAJOR TASKS}

- Identify materials and products performance attributes essential for retaining physical integrity (e.g., tensile strength after multiple high-low temperature cycling)

- Identify and evaluate existing test methods for physical properties and assess their adaptability to thermal conditions during and after a fire exposure

- Develop new methods that address gaps in the existing methods

$\frac{0}{4}$
$\frac{0}{2}$
0
0
$\frac{0}{2}$
$\frac{1}{2}$

- Identify, develop, and evaluate new composite materials - enable commercialization
Probability of Realization： $<50 \%$

\section{\begin{tabular}{l|l} 
TARGETS CONSIDERATIONS & C
\end{tabular}}

- Degree of physical integrity improvement s established for two to three principal applications, based on work with applications professionals

- Adaptation of existing test methods and, if necessary, development of new test methods to assure physical integrity

- Assessment of chemical approaches to providing significant and sufficient improvements in physical integrity

- Exploratory tests of products fabricated
Technology Transfer

- Compatibility with existing codes/ regulations

UNDESIRABLE CONSEQUENCES

- Potential for excessive fire protection

\section{from experimental composites}

- Conduct feasibility assessment of new composites

\section{$+r$}

\section{BENEFITS/IMPACTS}

Fire Losses (if not pursued): Uncertain

Medium Fire Losses (if successful): Potential for decreasing fire losses

N/A Environment and Human Health (if not pursued): Uncertain, material dependent

N/A Environment and Human Health (if successful): Uncertain, material dependent

Medium Cost of Meeting Fire Performance with Future Approaches: Could increase material cost but uncertain

Medium Other: Alternative material options with ability to withstand fires and maintain physical integrity 


\section{Highest Priority RESEARCH AND RECOMMENDATIONS}

Analysis of the break-out groups' reports revealed the following research recommendations. recommendations for research.

\subsection{Research on Priority Applications}

Priority Applications were defined as the most critical and urgent applications, in terms of overall impact on the fire problem, and, hence, should be a priority for fire safety and science research. The attendees identified 5 Priority Applications, which are listed below with a brief descriptor of what the attendees believed was needed to address the associated fire problem. The Priority Applications are listed in order of importance based on the attendee's input.

1. Residential Upholstered Furniture - Develop standardized tests, regulations, computational models, and compliance technologies that enable commercialization of affordable and environmental, health, and fire (both open flame and smoldering) safe upholstered furniture for residential homes.

2. Residential Buildings in WUI Communities - Develop standardized tests, building codes and regulations, computational models, and compliance technologies that harden homes from both ember and flaming ignition.

3. Multi-Story Timber Construction - Develop standardized tests, building codes and regulations, computational models, and compliance technologies that enable the safe use of structural timber (some of which could be exposed) for multi-story buildings.

4. Passenger Railway Cars - Develop standardized tests and help identify low cost compliance technologies for passenger railway cars.

5. High Rise Exterior Insulation - Develop standardized tests, building codes and regulations, computational models, and compliance technologies that enable the safe use of energy efficient insulation on the exterior of commercial buildings

\subsection{Research on Cross-Cutting Approaches}

Cross-Cutting Approaches were defined as critical needs that if addressed by research has the potential of solving several fire problems of several products in several applications, simultaneously. Though these 4 Cross-Cutting Apporaches were discussed in the context of the Priority Applications, the participants agreed they are applicable to any market where there are flammability requirements and should be the highest priority areas of research. This isn't a prioritized list (attendees didn't provide input).

- Real Fire Behaviors - Understand the end-use conditions and the product's vulnerabilities (firerelated) in real world applications. Specifically, gathering information on end-use factors that decrease a product's fire resistance over its service life and during a fire, and characteristics of the compliance enabling technologies and the products themselves that promote, and hinder fire spread and growth.

- Bench-Scale Tools - Develop bench-scale tools that accurately predict the product's fire behavior in a real fire and over product's service life and/or can be used for screening new compliance enabling technologies. Work with organizations to incorporate the predictive benchscale tools into relevant regulations and standards. Work with manufacturers to use bench-scale 
tools (predictive and screening) to identify (in their existing portfolio) and develop and use new compliant enabling technologies to reduce the flammability of their products.

- Engineered Fire Safe Products - Develop low cost, environment and human safe, and broadly implementable (universal) engineered material approaches that provide compliant fire resistance over the duration of the product's service life.

- Computational Tools - Develop computational tools to fill gaps in experimental data. This has many applications including, but not limited to, using the tools for compliance testing, predicting the fire behavior of a material and product over its service life, defining the mechanisms underpinning the product's fire behavior, and developing new engineered compliant enabling technologies.

Though the attendees didn't prioritize this list, based on the workshop discussions, research that delivers Bench Scale tools may be the highest priority because they have the potential to impact the entire flammability landscape - validated, predictive and screening bench tools could be the basis for standardized fire tests and fire regulations, and assist in commercialization of compliant enabling technologies and compliant products. Research that delivers Computational Tools may be equally as important because it allows the industry and researchers to expand and explore well beyond what we know experimentally, and accelerate $\mathrm{R} \& \mathrm{D}$, commercialization, and compliance testing. This combination of experimental (Bench or Real-Scale) and computational tools is needed to address the measurement science challenges associated with fire problems of today; in future, it will be critical. 


\subsection{Recommendations}

The following recommendations are based on the presentations, discussions, and break-out group reports.

1. It is recommended that research should primarily focus on the topics identified under CrossCutting - Real Fire Behaviors, Bench-Scale Tools, Engineered Fire Safe Products, and Computational Tools. These should be considered the highest priority for research because of their ability to impact a number of different fire problems.

2. To ensure the Cross-Cutting research is addressing problems of critical needs and in ways acceptable to the markets, it is recommended the research should target the applications identified under Priority Applications - Residential Upholstered Furniture, Residential Buildings in WUI Communities, Multi-Story Timber Construction, Passenger Railway Cars, and High Rise Exterior Insulation. These applications are considered to be a priority because of the overall impact on the fire problem.

3. To ensure the Cross-Cutting research is providing solutions that are acceptable to the markets, it is recommendation the researchers should partner with appropriate stakeholders (e.g.; standards, regulations, and code organizations, and manufacturers). Workshop recommended stakeholders are suggested in Figure 3.1 through Figure 3.12.

4. To guide the research in addressing the fire problems described in the Priority Applications, it is recommended to use the Tasks and Timelines provided in Figure 3.1 through Figure 3.12. However, it is recommended prior to doing so it is critical for the researchers to obtain additional information (e.g., realized or potential size of the fire problem) and develop an implementation plan aligned with their resources and organizations mission.

5. While it is responsibility of the organization to decide their role in the fire community, it is recommended that academia and government organizations, like NIST, may best be able to help the fire community (e.g.; researchers, industry, and standards agencies) by conducting research in a discovery mode. They (academia and government) should conduct research that removes the science and engineering challenges that prevent the development of tools (physical and computational) that will enable the development of testing standards and identifying new fire safe materials and chemistries. They should use this new understanding to develop and use these tools to identify and evaluate new compliance enabling materials and chemistries. They should then transfer the research finding to manufacturers and assist them in developing new commercial products. They should not conduct their research in a vacuum, but rather in collaboration with the relevant stakeholders (e.g.; industry). 


\section{SUMMARY}

NIST hosted workshop, Future Needs for Reducing the Fire Hazard of Materials, provided an opportunity for worlds experts to come together to discuss the challenges associated with reducing the fire hazards of existing and future products that compose the built and manufactured environment. A major product of the workshop is a prioritized list of research needs, applications, and guidance for implementing a research strategy to address these fire risks. This workshop report summarizes the results of the workshop and include the following recommendations.

The workshop report recommends that research on Cross-Cutting topics should be considered as the highest priority.

- Real Fire Behaviors

- Bench-Scale Tools

- Engineered Fire Safe Products

- Computational Tools

The workshop report recommends that the Cross-Cutting research should target Priority Applications in order to have the greatest impact on fire losses.

- Residential Upholstered Furniture

- Residential Buildings in WUI Communities

- Multi-Story Timber Construction

- Passenger Railway Cars

- High Rise Exterior Insulation.

The Fire Research Division at NIST intends to consider the input from this workshop as the Fire Research Division updates its roadmap for addressing the measurement science gaps that are preventing the nation from developing low fire hazard products now and in the future. We also believe the report can be used for establishing research directions for other public organizations, academia, and the private sector. 


\section{APPENDIX A. CONTRIBUTORS}

\section{Name Organization}

David Barber

Melanie Biggs

Jason Bragg

Morgan Bruns

Dan Cheney

Tyler Congleton

Rick Davis

Manfred Döring

Douglas Fox

Richard Gann

Mark Gentile

Christina Guthrie

Steve Gwynne

Meghan Housewright

Yuan $\mathrm{Hu}$

Marc Janssens

David Johnston

Baljinder Kandola

Bernard Kennedy

Yoon Ko

Erica Kuligowski

Brian Lattimer

Isaac Leventon

Andrew Lock

David Mao

Nathan Marsh

Alex Morgan

Charles Olsen

Steve Roman

David Schiraldi

Paul Shipp

Melissa Shurland

Jason Smart

Usman Sorathia

Stas Stoliarov

Kuma Sumathipala

Yu-Zhong Wang

Zhengzhou Wang

Jay West

Mauro Zammarano
Arup

Consumer Product Safety Commission

Owens Corning

National Institute of Standards and Technology

Boise Cascade

Boise Cascade

National Institute of Standards and Technology

Fraunhofer Institute

American University

National Institute of Standards and Technology

U.S. Department of Transportation

U.S. Environmental Protection Agency

National Research Council Canada

National Fire Protection Association

University of Science and Technology of China

Southwest Research Institute

Vinyl Siding Institute

University of Bolton

U.S. Department of Transportation

National Research Council Canada

National Institute of Standards and Technology

Jensen Hughes

National Institute of Standards and Technology

Consumer Product Safety Commission

U.S. Department of Transportation

National Institute of Standards and Technology

University of Dayton Research Institute

AB Specialty Silicones

LTK Engineering

Case Western University

USG (Gypsum)

U.S. Department of Transportation

American Wood Council

U.S. Navy

University of Maryland

American Wood Council

Sichuan University

Tongji University

American Chemistry Council

National Institute of Standards and Technology 


\section{APPENDIX B. ACRONYMS/ABBREVIATIONS}

$\mathrm{ACC}$

ASCE

ASTM

AFMA

AWC

BEARHFTI

CFAST

CLT

CPI

CPSC

DOT

EHS

EPA

EV

FR

FRT

FRA

HRR

IBC

ISO

MW

NASFM

NFPA

NIST

PFA

SDO

TB

TBD

TLCP

TN

UFPA

UL

USDA
American Chemistry Council

American Society of Civil Engineers

ASTM International; formerly The American Society for Testing and Materials

American Furniture Manufacturers Association

American Wood Council

Bureau of Electronic and Appliance Repair, Home Furnishings and Thermal Insulation

Consolidated Fire and Smoke Transport Model

cross laminated timber

Center for the Polyurethane Industries, a Division of the American Chemistry Council

U.S. Consumer Product Safety Commission

U.S. Department of Transportation

environment, health, and safety

U.S. Environmental Protection Agency

electric vehicle

flame retardant

fire retardant treatment or fire retardant treated

Federal Railroad Administration

heat release rate

International Building Code

International Standards Organization

megawatts

National Association of State Fire Marshals

National Fire Protection Association

National Institute of Standards and Technology

Polyurethane Foam Association

Standards Development Organization

Technical Bulletin

to be determined

thermotropic liquid crystal polymers

Technical Note

Upholstered Furniture Action Council

Underwriters Laboratories

U.S. Department of Agriculture 


\section{Appendix C. Agenda}

\section{Workshop: Future Needs for Reducing the Fire Hazard of Materials}

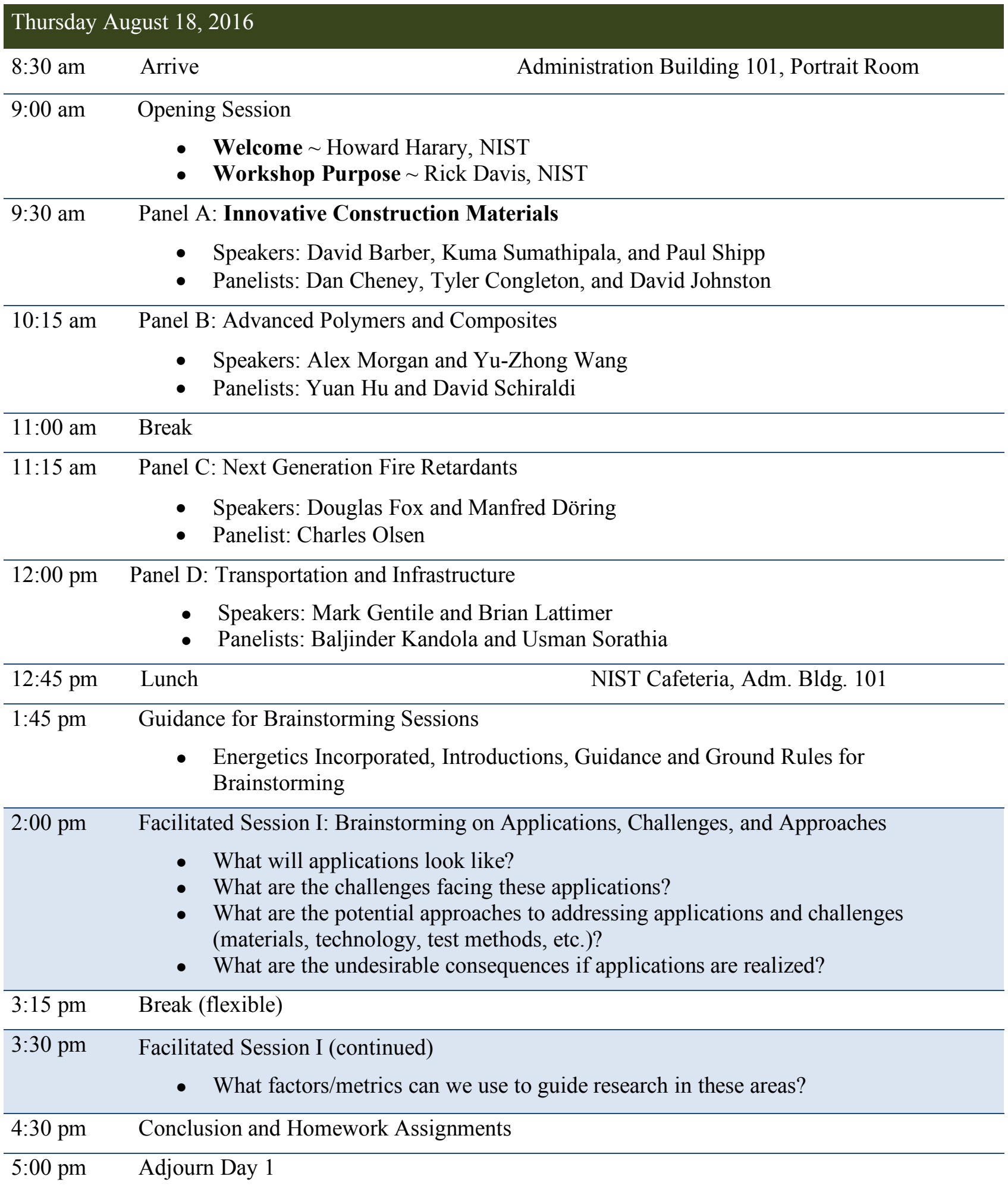




\section{Friday August 19, 2016}

8:30 am Arrive Administration Building 101, Room A

9:00 am Welcome and Review Previous Day - Applications, Challenges, and Approaches

- Have we missed any major applications and approaches?

- Are there significant challenges or gaps that have not been identified?

- Are there emerging approaches that could impact many applications?

\begin{tabular}{lcl}
\hline 9:15 am & Guidance for Breakouts \\
& - Priority Topics and Action Plans \\
\hline 9:45 am & Break and Move to Breakouts Administration Building 101, Rooms A, B, \&D \\
\hline 9:45 am & Breakout Session: Approaches and Pathways \\
& - What research is needed to move forward with approaches/solutions and fill gaps? \\
& - What are the undesirable consequences if successful at applying approaches? \\
& - $\quad$ Develop potential action plans for top approaches and challenges \\
\hline 12:30 pm & Lunch & \\
\hline $1: 30 \mathrm{pm}$ & Update & NIST Cafeteria, Bldg. 101 \\
\hline 2:00 pm & Closing Comments & \\
\hline
\end{tabular}

Adjourn 